\title{
A Novel Approach for Controlling the Band Formation in Medium Mn Steels
}

\begin{abstract}
H. FARAHANI, W. XU, and S. VAN DER ZWAAG
Formation of the microstructural ferrite/pearlite bands in medium Mn steels is an undesirable phenomenon commonly addressed through fast cooling treatments. In this study, a novel approach using the cyclic partial phase transformation concept is applied successfully to prevent microstructural band formation in a micro-chemically banded $\mathrm{Fe}-\mathrm{C}-\mathrm{Mn}-\mathrm{Si}$ steel. The effectiveness of the new approach is assessed using the ASTM E1268-01 standard. The cyclic intercritical treatments lead to formation of isotropic microstructures even for cooling rates far below the critical one determined in conventional continuous cooling. In contrast, isothermal intercritical experiments have no effect on the critical cooling rate to suppress microstructural band formation. The origin of the suppression of band formation either by means of fast cooling or a cyclic partial phase transformation is investigated in detail. Theoretical modeling and microstructural observations confirm that band formation is suppressed only if the intercritical annealing treatment leads to partial reversion of the austenite-ferrite interfaces. The resulting interfacial $\mathrm{Mn}$ enrichment is responsible for suppression of the band formation upon final cooling at low cooling rates.
\end{abstract}

https://doi.org/10.1007/s11661-018-4565-8

(C) The Author(s) 2018. This article is an open access publication

\section{INTRODUCTION}

THE formation of ferrite/pearlite microstructural bands in hot-rolled low-alloy steels has been one of the main challenges in the development of medium $\mathrm{Mn}$ steels for low-weight automotive applications. ${ }^{[1-3]}$ The presence of the ferrite/pearlite microstructural banding leads to an undesirable reduction of the mechanical properties perpendicular to the rolling direction. ${ }^{[4-10]}$ The band formation is the result of significant partitioning of alloying elements during solidification which generally cannot be undone sufficiently during the solid-state homogenization treatments preceding the hot rolling and subsequent thermomechanical processing steps. Not surprisingly, the topic of band formation and its relation to the imposed thermal trajectory when cooling down from the hot rolling temperature has been researched for more than 50 years. ${ }^{[1-16]}$

In micro-chemically banded Fe-C-Mn-Si steels, the spatial variation of substitutional alloying element concentrations locally reduces (in regions with high

H. FARAHANI and S. VAN DER ZWAAG are with the Novel Aerospace Materials Group, Faculty of Aerospace Engineering, Delft University of Technology, Delft, The Netherlands. Contact e-mail: H.Farahani@tudelft.nl W. XU is with the State Key Laboratory of Rolling and Automation, Northeastern University, Shenyang, 110819 China.

Manuscript submitted November 1, 2017.

Article published online March 9, 2018 levels of austenite forming elements such as $\mathrm{Mn}$ ) or raises (in regions with high levels of ferrite forming elements such as $\mathrm{Si}$ ) the $\mathrm{A}_{3}$ transition temperature. Upon cooling from the austenite, the ferrite starts to nucleate in regions with a high $\mathrm{A}_{3}$ transition temperature as the required undercooling for ferrite nucleation is reached there first. With the formation of the early ferrite, $\mathrm{C}$ is injected into the remaining neighboring austenite with a higher Mn content, reducing the local $\mathrm{A}_{3}$ transition temperature even more. Upon further cooling, the composition in these remaining austenitic regions reaches eutectoid levels and the austenite decomposition continues with pearlite formation in a banded arrangement. ${ }^{[17]}$ Hence, formation of the ferrite/pearlite microstructural bands is a matter of balancing nucleation and growth during austenite decomposition. ${ }^{[5,18]}$ In a standard approach, formation of microstructural bands can be suppressed via fast cooling after hot rolling. The severe undercooling from austenitization temperature results in simultaneous nucleation of ferrite in both rich and poor Mn-containing regions. Although fast cooling prevents band formation, but it leads to formation of ferrite with a fine average grain size and a higher hardness and yield strength which is not always desirable.

Recently, the 'Cyclic Partial Phase Transformation' (CPPT) approach has been proposed as an scientifically interesting intercritical annealing route to investigate the effect of alloying elements on interface migration kinetics. ${ }^{[19,20]}$ In a CPPT experiment, the temperature is 
cycled between two temperatures inside the austenite-ferrite two-phase regime such that both austenite and ferrite phases are present at all times. The CPPT experiments demonstrate a clear retardation of the final ferrite growth as a result of local Mn enrichment due to the back and forth migration of the austenite-ferrite interfaces more or less following the same trajectory. ${ }^{[21]}$ In a more recent approach, the cyclic treatments are successfully used as a novel route to stabilize austenite in a medium Mn steel down to room temperature. ${ }^{[22]}$

The present work introduces a new approach for controlled suppression of ferrite/pearlite band formation in a medium Mn steel using the CPPT approach and making use of the controlled Mn partitioning at moving austenite-ferrite interfaces. The approach led to a considerable lowering of the minimum cooling rate required to prevent band formation. The unique observation of perfectly aligned pearlite rims around ferrite grains is a clear evidence of the impact of local $\mathrm{Mn}$ enrichment at halted interfaces.

\section{EXPERIMENTAL DETAILS}

In this study, a commercial hot-rolled Fe-0.17C-1.47Mn-1.48Si (all concentrations in mass pct.) steel grade is subjected to different thermal treatments. Solid cylindrical samples for dilatometric experiments with a diameter of $5.0 \mathrm{~mm}$ and length of $10.0 \mathrm{~mm}$ were wire-cut with the axis of the cylinder parallel to the rolling direction. Qualitative energy dispersive spectroscopy (EDS) across the rolling direction in the samples was done confirming micro-chemical banding of both $\mathrm{Mn}$ and $\mathrm{Si}$. All thermal processing was done using a Bähr DIL 805A/D/T Quenching dilatometer. As samples containing micro-chemical bands show different dilatation signals parallel and perpendicular to the rolling direction, ${ }^{[23]}$ the dilatation of the specimens was measured in both the longitudinal and lateral direction. The samples were aligned such that the rolling plane was perpendicular to the direction in which the lateral expansion was measured. All experiments were done in vacuum with a pressure of $5 \times 10^{-4} \mathrm{mbar}$. Two thermocouples spaced $4 \mathrm{~mm}$ apart were spot welded to the samples to ascertain that the thermal gradient along the sample was less than $3 \mathrm{~K}$. All samples were heated with a rate of $10 \mathrm{~K} / \mathrm{s}$ and fully austenitized at $1273 \mathrm{~K}$ $\left(1000{ }^{\circ} \mathrm{C}\right.$ ) for 300 seconds (5 minutes) and then subjected to either Continuous Cooling (CC) experiments with different cooling rates (CR) from 20 to $0.17 \mathrm{~K} / \mathrm{s}(10$ $\mathrm{K} / \mathrm{min}$ ) or to different Cyclic Partial Phase Transformation (CPPT) routes. The samples were cut in the longitudinal direction and polished and etched with a 2 pct Nital etchant and subsequently evaluated using conventional light and scanning electron microscopical methods. The micro-segregation of $\mathrm{C}, \mathrm{Mn}$, and $\mathrm{Si}$ was determined using a Jeol JXA 8900R microprobe instrument fitted with appropriate wavelength dispersive spectrometers.

\section{RESULTS}

First, the results of cooling rate experiments on the ferrite/pearlite band formation during continuous cooling (CC) experiments are presented. Figures 1(a) and (b) show the dilatation curves in longitudinal and lateral directions for continuous cooling experiments with cooling rates $(\mathrm{CR})$ of $20,10,5,4,3,2,1,0.5$, and 0.17 $\mathrm{K} / \mathrm{s}(10 \mathrm{~K} / \mathrm{min})$, respectively. In these graphs, the dilatation with respect to the dilatation at the end of the austenitisation treatment is plotted. The increase in length during cooling reflects decomposition of austenite. For low cooling rates, the dilatation curves indicate a two-step process of ferrite formation followed by pearlite formation, while at higher cooling rates, a two-step ferrite-bainite/martensite reaction is observed. The difference between the ferrite nucleation start

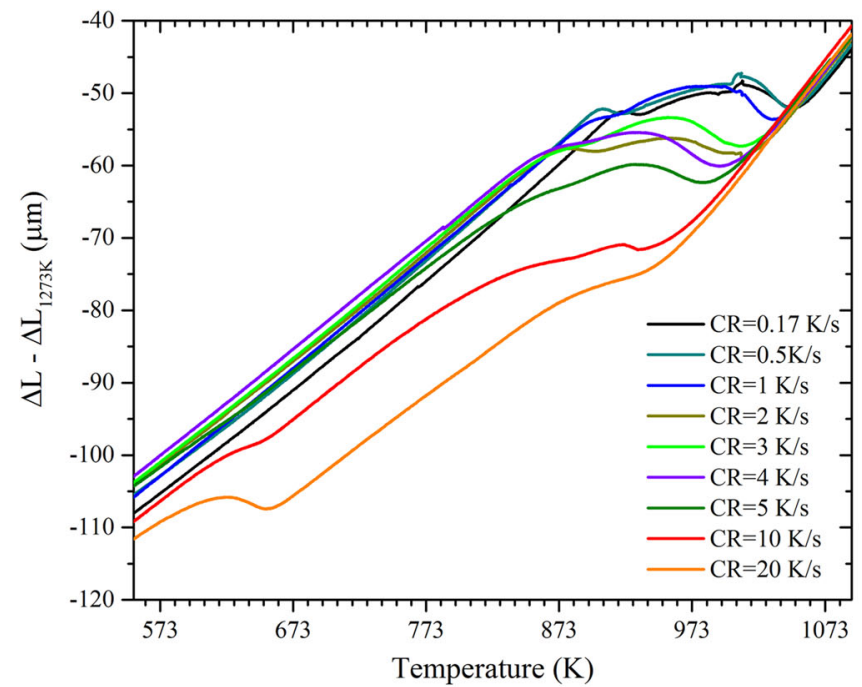

(a)

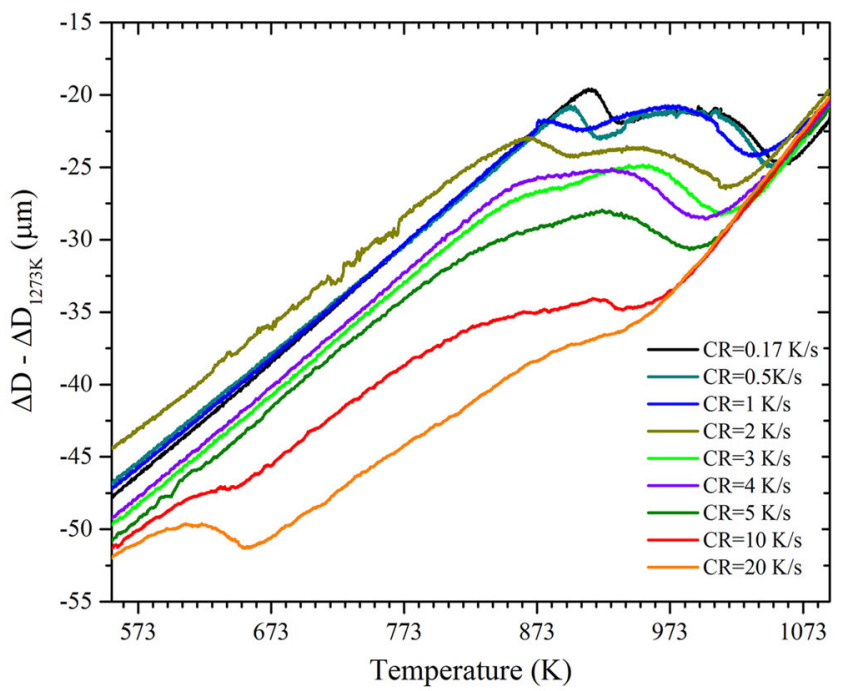

(b)

Fig. 1-Dilatation curves achieved in $\mathrm{CC}$ experiments in $(a)$ longitudinal direction and $(b)$ lateral direction. 
temperature $\left(T_{\mathrm{s}}\right)$ and transformation end temperature $\left(T_{\mathrm{e}}\right)$ increases significantly with increasing cooling rate. For example, in the curve of $\mathrm{CR}=1 \mathrm{~K} / \mathrm{s}$, austenite decomposition starts at $T_{\mathrm{s}}=1040 \mathrm{~K}\left(767^{\circ} \mathrm{C}\right)$ and finishes at $T_{\mathrm{e}}=896 \mathrm{~K}\left(623{ }^{\circ} \mathrm{C}\right)$, while for $\mathrm{CR}=10$ $\mathrm{K} / \mathrm{s}, T_{\mathrm{s}}=982 \mathrm{~K}\left(709^{\circ} \mathrm{C}\right)$ and $T_{\mathrm{e}}=625 \mathrm{~K}\left(352{ }^{\circ} \mathrm{C}\right) . \mathrm{A}$ comparison of the dilatation curves parallel and perpendicular to the sample (i.e., to the rolling direction) shows that at relatively low cooling rates, the dilatation due to the pearlite formation is much more significant in the lateral dilatation curves than in the axial dilation curves. Earlier work ${ }^{[23]}$ has shown that such a difference in the relative dilatation due to the pearlite formation is a clear sign of band formation. At higher cooling rates, the axial and radial dilatation curves become more equal, indicative of a more isotropic microstructure.

Figures 2(a) through (i) show the microstructures achieved after $\mathrm{CC}$ experiments with different cooling rates. For low cooling rates of $0.17,0.5$, and $1 \mathrm{~K} / \mathrm{s}$, the microstructures in Figures $2(\mathrm{~g})$ through (i) display well-developed ferrite/pearlite bands parallel to the rolling direction. The pearlitic regions are the dark

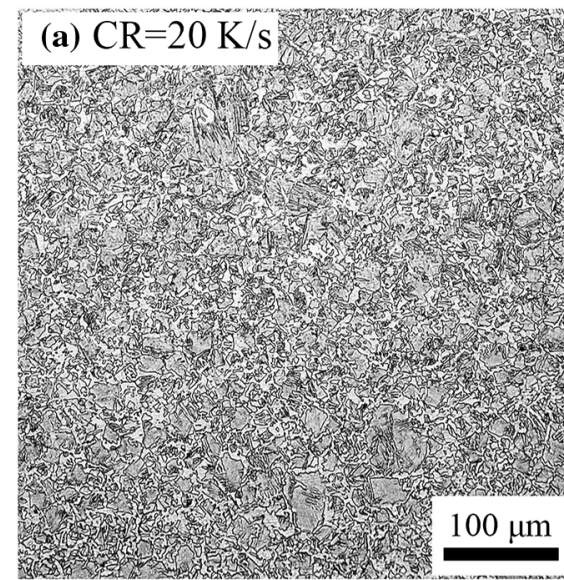

(d) $\mathrm{CR}=4 \mathrm{~K} / \mathrm{s}$, f

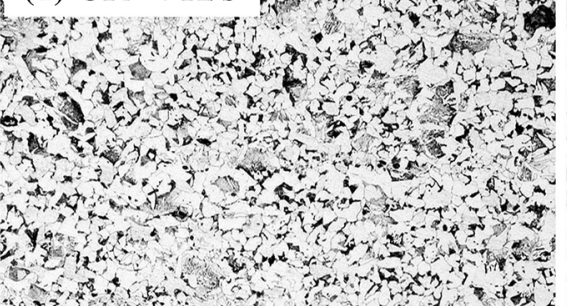

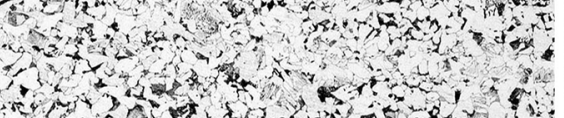

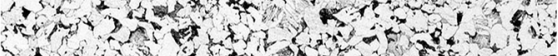

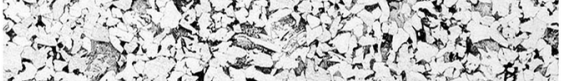

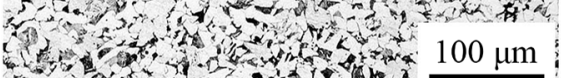

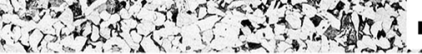

(g) $\mathrm{CR}=1 \mathrm{~K} / \mathrm{s}$.

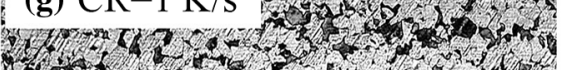

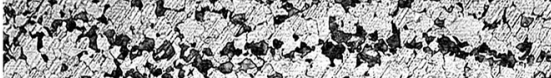

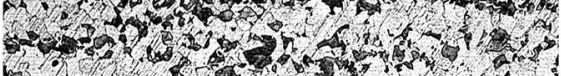

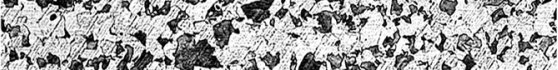

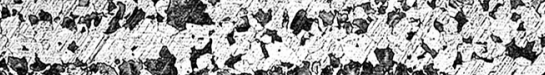

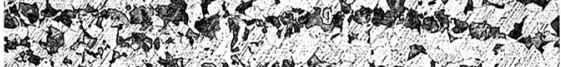

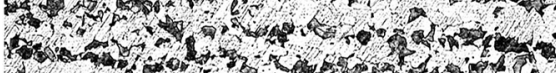
-

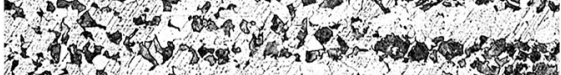

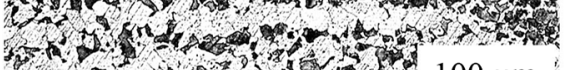
1)
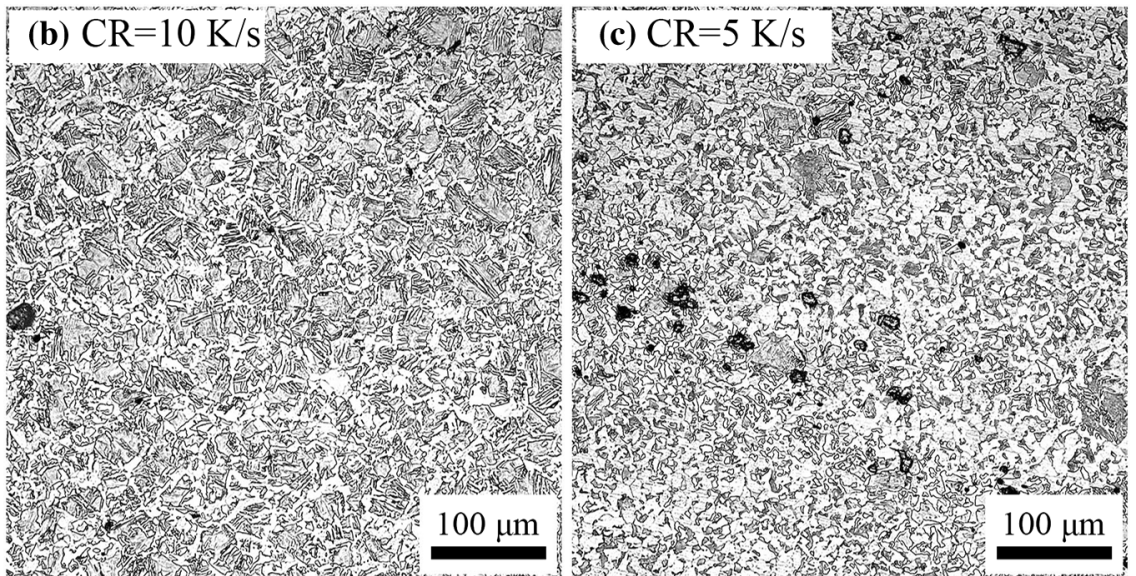

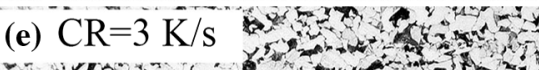

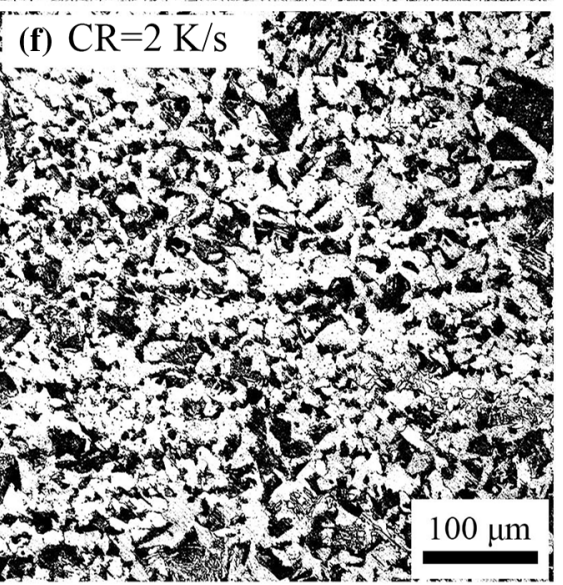

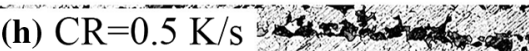
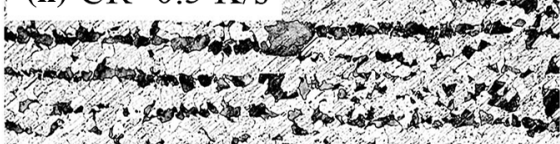

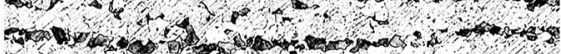

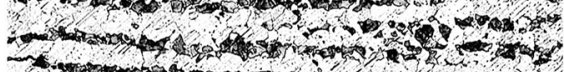
6.200

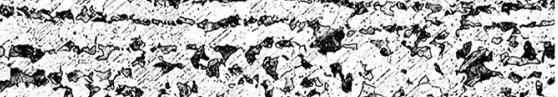

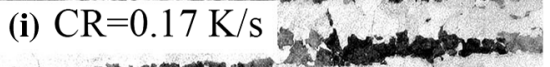

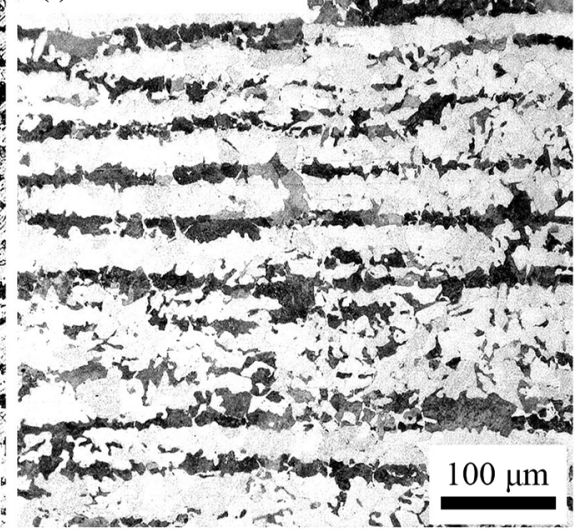

Fig. 2-Microstructure after continuous cooling experiments with different cooling rates of $(a) 20 \mathrm{~K} / \mathrm{s}$, $(b) 10 \mathrm{~K} / \mathrm{s}$, $(c) 5 \mathrm{~K} / \mathrm{s},(d) 4 \mathrm{~K} / \mathrm{s},(e) 3 \mathrm{~K} / \mathrm{s}$, (f) $2 \mathrm{~K} / \mathrm{s},(g) 1 \mathrm{~K} / \mathrm{s},(h) 0.5 \mathrm{~K} / \mathrm{s}$, and $(i) 0.17 \mathrm{~K} / \mathrm{s}(10 \mathrm{~K} / \mathrm{min})$. 
phase in these figures. The ferrite and pearlite grains are formed in rows with a spacing of $\sim 50 \mu \mathrm{m}$. For samples subjected to cooling rates of 2,3 , and $4 \mathrm{~K} / \mathrm{s}$, ferritic/pearlitic microstructures are observed (Figures 2(d) through (f)), but the microstructural components are more randomly distributed with no noticeable sign of preferential band formation. The microstructures of samples after CC experiments with cooling rates of 5 , 10 , and $20 \mathrm{~K} / \mathrm{s}$ in Figures 2(a) through (c) consist of ferrite, pearlite, and bainite or martensite phases ${ }^{[24]}$ (and possibly fractions of retained austenite); all phases are distributed homogeneously across the microstructure. These micrographs demonstrate that for this alloy and linear cooling, a cooling rate of $2 \mathrm{~K} / \mathrm{s}$ is the critical rate below which the resulting microstructure shows fully banded characteristics with distinct rows of ferrite and pearlite formed. Banding can only be avoided with cooling rates equal or higher than $2 \mathrm{~K} / \mathrm{s}$.

The dilatation curves for $\mathrm{CC}$ experiments in longitudinal (Figure 3(a)) and lateral (Figure 3b) directions for a band forming $(\mathrm{CR}=0.5 \mathrm{~K} / \mathrm{s})$ and a non-band forming $(\mathrm{CR}=5 \mathrm{~K} / \mathrm{s})$ condition, respectively, are in line with the microstructural observations in Figure 2. In the dilatation curve for a cooling rate of $0.5 \mathrm{~K} / \mathrm{s}$, the lateral expansion due to pearlite formation, between $900 \mathrm{~K}$ and $920 \mathrm{~K}\left(627^{\circ} \mathrm{C}\right.$ to $\left.647^{\circ} \mathrm{C}\right)$, is noticeably more pronounced than the axial dilatation over this temperature domain, while for $\mathrm{CR}=5 \mathrm{~K} / \mathrm{s}$, the relative contributions of the second dilatation peak are comparable for both sets of data.

As explained above, in order to avoid ferrite/pearlite band formation in a CC experiment, cooling faster than the critical cooling rate of $2 \mathrm{~K} / \mathrm{s}$ is essential. In the next section, new routes of intercritical annealing using the CPPT approach are explained and the results are presented.

Figures 4(a) through (d) show different applied intercritical annealing routes with cooling/heating rates of $0.17 \mathrm{~K} / \mathrm{s}(10 \mathrm{~K} / \mathrm{min})$ as well as the CC route with the same CR (in red). In type H1 CPPT (Figure 4(a)), after continuous cooling to $T_{1}=998 \mathrm{~K}\left(725^{\circ} \mathrm{C}\right)$, the sample is held isothermally for 20 minutes and then heated to $T_{2}=1048 \mathrm{~K}\left(775^{\circ} \mathrm{C}\right)$, held again isothermally for 20 minutes (total isothermal holding for 40 minutes), followed by cooling at $0.17 \mathrm{~K} / \mathrm{s}$ to room temperature. In type H2 CPPT (Figure 4(b)), the intercritical reheating-cooling cycle is imposed twice before final cooling down. In type I CPPT (Figure 4(c)), after reaching $T_{1}$, the temperature is increased gradually to $T_{2}$ such that the reheating time is equivalent to the total isothermal holding and heating times in type H1, i.e., 40 minutes. Finally, in the isothermal experiment (Figure 4(d)), after cooling from the austenitization temperature, the sample is held isothermally at $1048 \mathrm{~K}\left(775^{\circ} \mathrm{C}\right)$ for 40 minutes, prior to final cooling down at the usual cooling rate.

In Figure 5, the longitudinal dilatation curves for each of the intercritical annealing experiments described above are presented and compared to those of the corresponding $\mathrm{CC}$ experiment. In the type $\mathrm{H} 1 \mathrm{CPPT}$ experiment (Figure 5(a)), after reaching $T_{1}=998 \mathrm{~K}$ $\left(725^{\circ} \mathrm{C}\right)$, ferrite formation continues isothermally, and there is a linear increase in sample length due to heating after isothermal holding. The sudden jump in the sample length at around $T=1010 \mathrm{~K}\left(737^{\circ} \mathrm{C}\right)$, both in cyclic and $\mathrm{CC}$ curves, is an artifact and is due to a change in the magnetic properties of the alloy upon reaching the Curie temperature. ${ }^{[25-27]}$ The linear increase in the sample length during heating after isothermal holding in the CPPT curve corresponds to the so-called 'stagnant stage' during which the transformation is suppressed due to pinning effect of segregated $\mathrm{Mn}$ atoms at austenite-ferrite interfaces. ${ }^{[19,20]}$ Upon reaching $T_{2}=1048 \mathrm{~K}\left(775^{\circ} \mathrm{C}\right)$, ferrite to austenite back transformation starts to occur isothermally. In the final cooling stage, first the sample shrinks linearly down to $T \approx 973 \mathrm{~K}\left(700^{\circ} \mathrm{C}\right)$, and then after a non-linear decreasing stage, the dilatation curve shows a delayed increase in the length at $\mathrm{T} \approx 923 \mathrm{~K}\left(650^{\circ} \mathrm{C}\right)$ reflecting the delay in the final ferrite/pearlite formation. It is worth to point out that the pearlite formation in type $\mathrm{H} 1$ CPPT finishes at $T_{\mathrm{e}} \approx 898 \mathrm{~K}\left(625^{\circ} \mathrm{C}\right)$, whereas in the $\mathrm{CC}$ experiment, the pearlite formation finishes at a significantly higher temperature of $T_{\mathrm{e}} \approx 910 \mathrm{~K}\left(637^{\circ} \mathrm{C}\right)$.

The dilatation behavior for the type $\mathrm{H} 2$ CPPT experiment, Figure 5(b), is similar to that for type H1 but linear contraction corresponding to the stagnant stage in austenite decomposition during final cooling continues down to $T \approx 960 \mathrm{~K}\left(687^{\circ} \mathrm{C}\right)$ instead of $T \approx 973 \mathrm{~K}\left(700{ }^{\circ} \mathrm{C}\right)$ measured in the type $\mathrm{H} 1$ route. In type I CPPT (Figure 5(c)), after reaching $T_{1}$, despite the increase in temperature and the expected decrease in length due to ferrite to austenite transformation, the

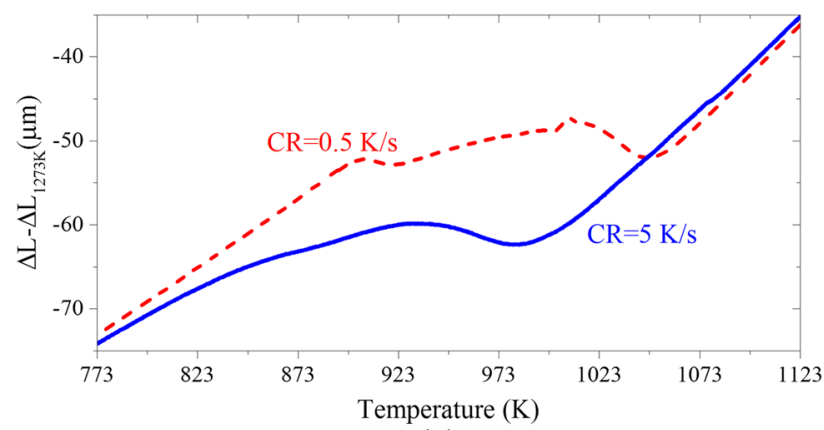

(a)

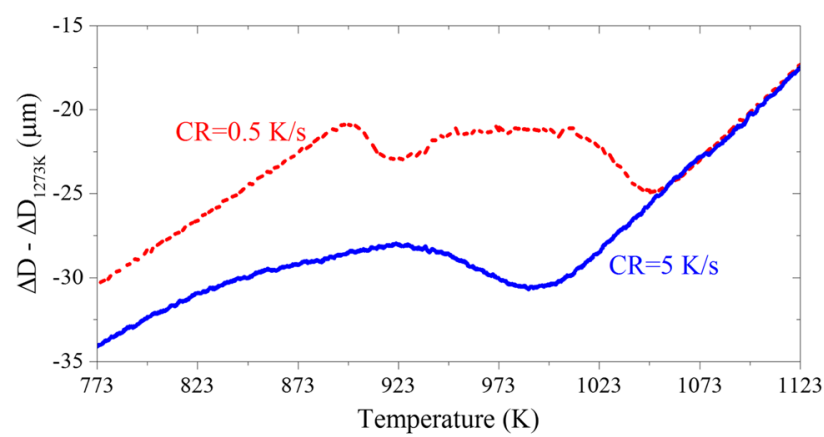

(b)

Fig. 3 - Comparison between dilatation curves achieved by continuous cooling experiment with the rate of $0.5 \mathrm{~K} / \mathrm{s}$ (leading to band formation) and $5 \mathrm{~K} / \mathrm{s}$ (no band formation) in (a) longitudinal and (b) lateral direction. 


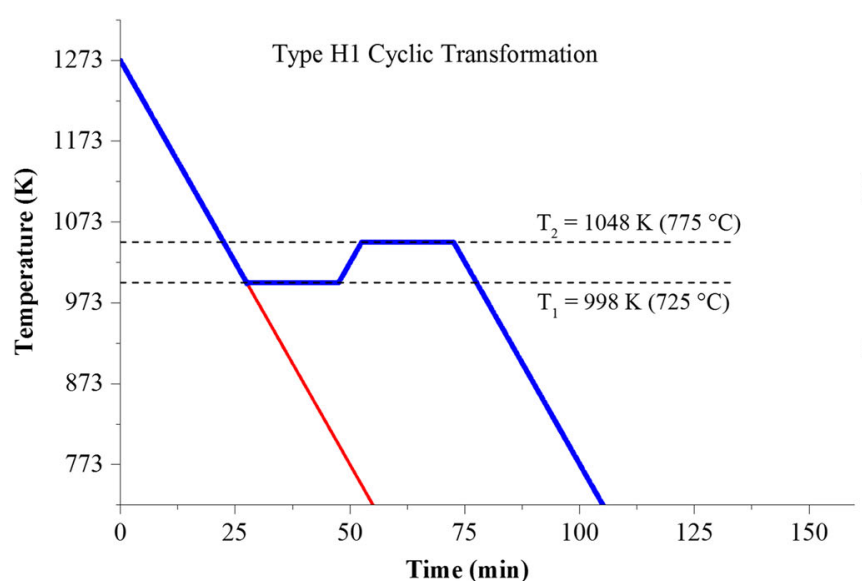

(a)

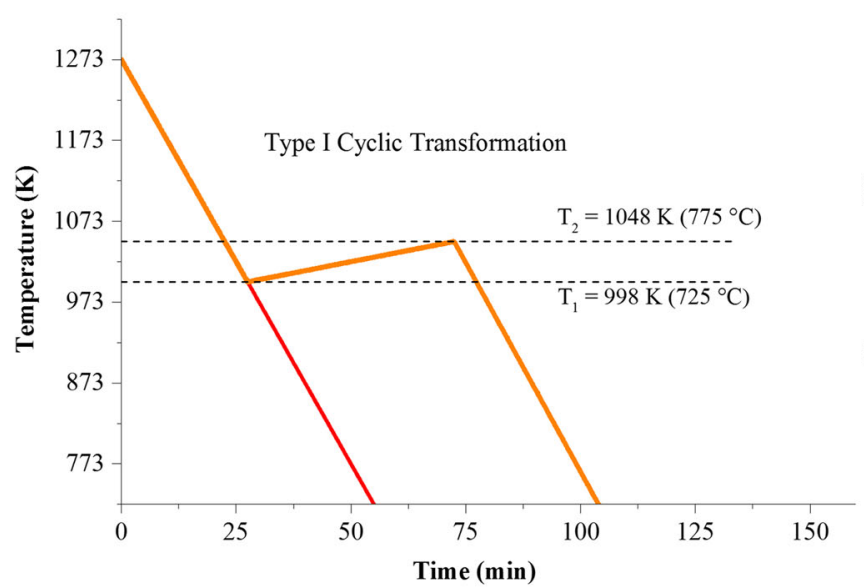

(c)

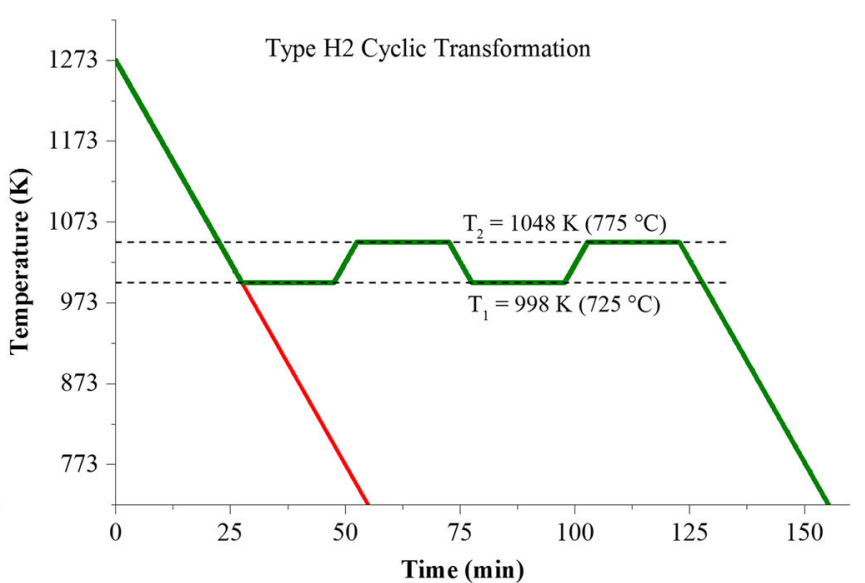

(b)

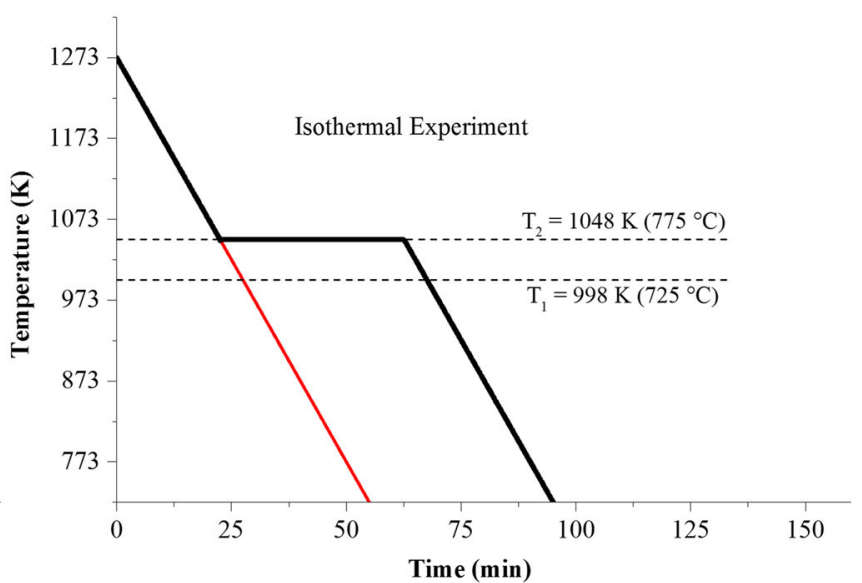

(d)

Fig. 4-The CC experiment with $\mathrm{CR}=0.17 \mathrm{~K} / \mathrm{s}$ vs different intercritical annealing routes of $(a)$ type H1 CPPT, (b) type H2 CPPT, $(c)$ type I CPPT, and $(d)$ isothermal experiment.

sample length increases non-linearly for about $15 \mathrm{~K}$. This stage is called 'inverse transformation' and is explained by non-equilibrium condition around the austenite-ferrite interface due to incomplete redistribution of $\mathrm{C}$ atoms after sudden change in the temperature regime. ${ }^{[19,20]}$ After the inverse transformation stage, the stagnant stage starts and continues during cooling similar to that of type $\mathrm{H} 1$ and $\mathrm{H} 2 \mathrm{CPPT}$ routes. Finally, in the isothermal experiment (Figure 5(d)), the austenite to ferrite transformation proceeds isothermally and upon further cooling, the dilatation behavior is analogous to that of the $\mathrm{CC}$ curve with no sign of delayed austenite decomposition during final cooling.

The observed differences between the dilatation behavior after the various intercritical annealing treatments and the continuous cooling experiment with the same CR are reflected in the radically different final microstructures shown in Figure 6. The microstructure after type H1 CPPT (Figure 6(a)), has no significant evidence of ferrite/pearlite band formation notwithstanding its final cooling rate $(0.17 \mathrm{~K} / \mathrm{s})$ being well below the critical cooling rate of $2 \mathrm{~K} / \mathrm{s}$ determined by $\mathrm{CC}$ experiment. Similarly, treatments of the type $\mathrm{H} 2$ (Figure 6(b)) and I (Figure 6(c)) lead to non-banded microstructures. These microstructures consist of homogenously distributed ferrite and pearlite grains, despite the applied low cooling rate. In contrast, the microstructure of isothermal experiment (Figure 6(d)) still shows significant broad bands of ferrite/pearlite parallel to the rolling direction.

Having presented the effectiveness of CPPT treatment in suppression of the band formation at a final cooling rate of $0.17 \mathrm{~K} / \mathrm{s}$, the intercritical type $\mathrm{H} 1$ treatment has also been applied but with higher final cooling rates of 0.5 and $1 \mathrm{~K} / \mathrm{s}$. Figures 7 (a) through (c) show the longitudinal dilatation curve for type H1 CPPT with CR = 0.5 and $1 \mathrm{~K} / \mathrm{s}$, respectively. In these figures, the corresponding CC curves are also plotted. In both cyclic experiments, the ferrite formation after the cyclic experiment is significantly retarded compared to that in the $\mathrm{CC}$ experiment. The corresponding microstructures in Figures 7(b) through (d), show that band formation is more reduced after the type $\mathrm{H} 1$ cyclic experiment with $\mathrm{CR}=0.5 \mathrm{~K} / \mathrm{s}$ compared to the $\mathrm{CR}=1 \mathrm{~K} / \mathrm{s}$. This gives an impression that CPPT experiment with lower CR is more effective in controlling the band formation, while in the $\mathrm{CC}$ experiments, banding is reduced as a result of the higher cooling rate. 


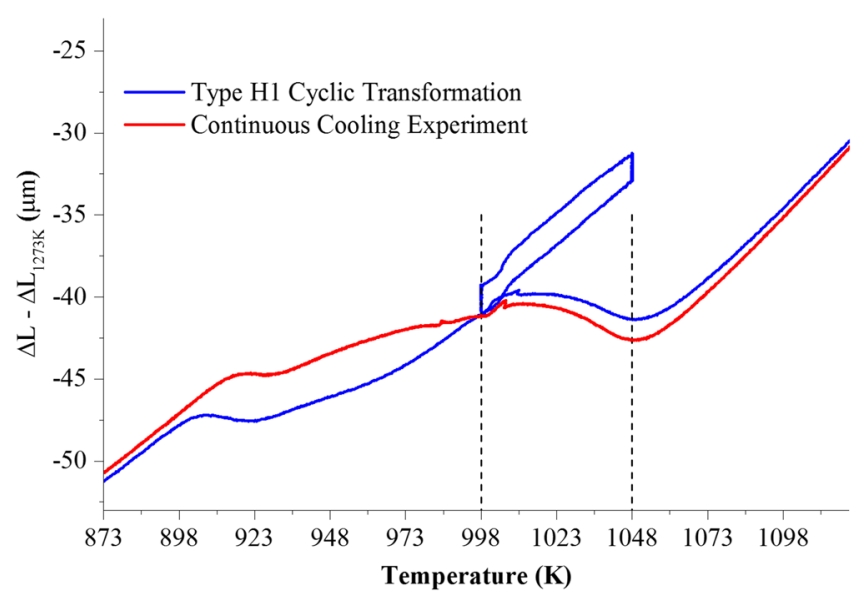

(a)

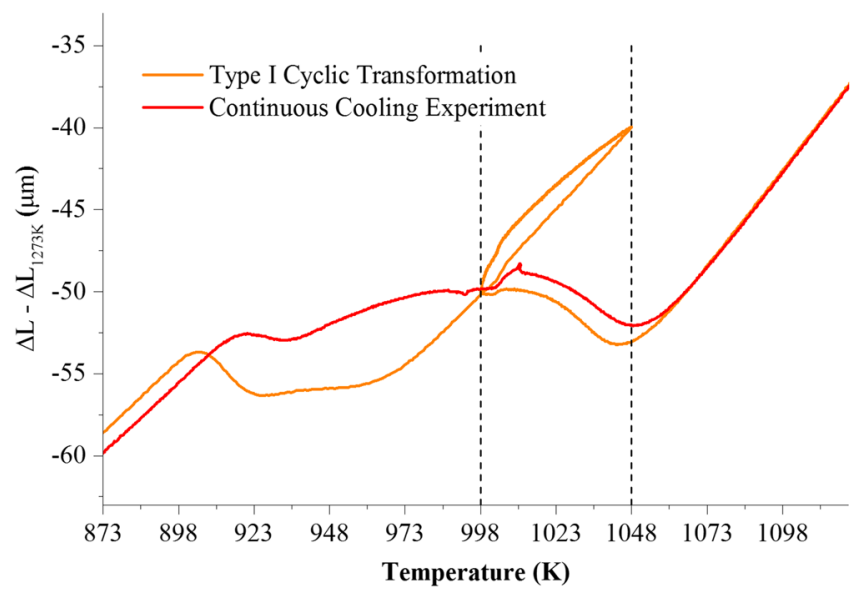

(c)

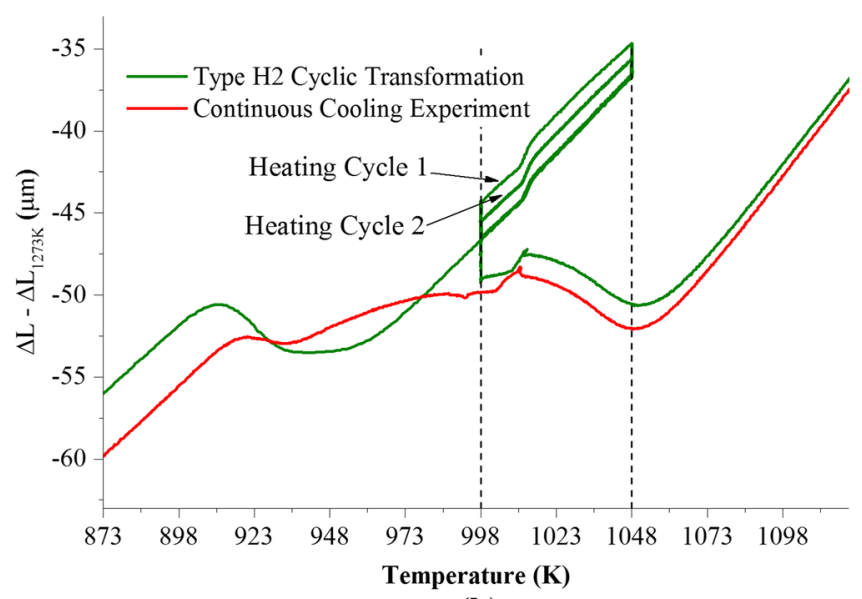

(b)

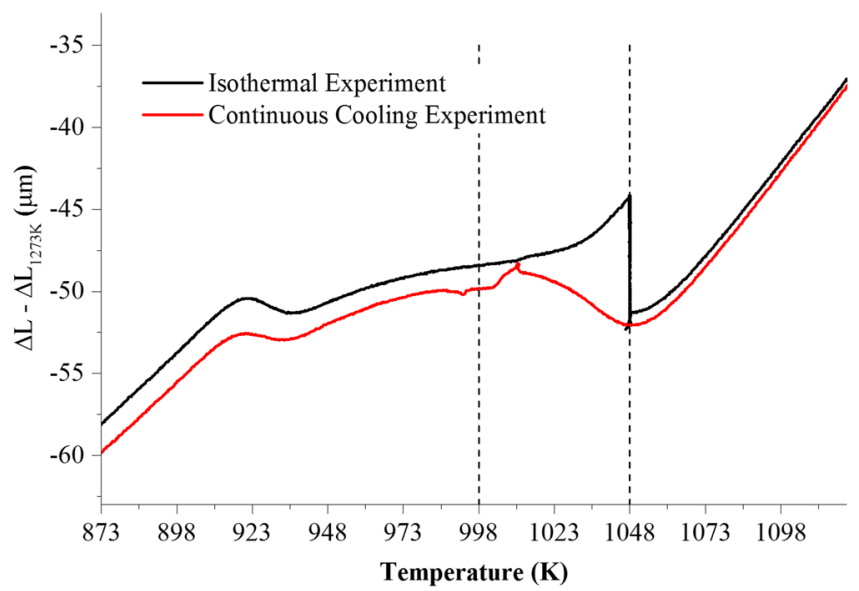

(d)

Fig. 5-Dilatation curves after different (a) type H1, (b) type H2, (c) type I CPPT, and $(d)$ isothermal experiment compared to continuous cooling curve with $\mathrm{CR}=0.17 \mathrm{~K} / \mathrm{s}$.

The extent of ferrite/pearlite banding can be quantified by the anisotropy index (AI) as defined in the industrial ASTM E1268-01 standard. ${ }^{[28]}$ In this standard method, the degree of banded or oriented microstructures is quantified using statistical measurements on the morphological appearance of certain microstructural features. AI values close to 1 belong to samples which do not exhibit banding and AI values bigger than 1 indicate microstructures showing increasingly noticeable band formation levels. Figure 8 shows the AI values for all microstructures created via intercritical annealing routes or $\mathrm{CC}$ experiments as a function of the applied cooling rate. The error bars in AI refer to the standard deviation in the measurements. Continuous cooling with rates equal or higher than $2 \mathrm{~K} / \mathrm{s}$ leads to fully isotropic microstructures, i.e., AI values equal to 1 . The degree of banding increases extensively with decreasing cooling rates, to an anisotropy index of 6 for a $\mathrm{CC}$ experiment with $\mathrm{CR}=0.17 \mathrm{~K} / \mathrm{s}$. All CPPT experiments with a slow cooling rate of $0.17 \mathrm{~K} / \mathrm{s}$ show isotropic microstructures with an $\mathrm{AI}$ value $<1$. In the type $\mathrm{H} 1 \mathrm{CPPT}$ experiment, the anisotropy index increases with increasing cooling rate. For $\mathrm{CR}=1 \mathrm{~K} / \mathrm{s}$, there is no difference between AI values achieved from microstructures after cyclic treatment (Figure 7(d)) and continuous cooling (Figure 2(g)). The AI value of microstructure after the isothermal experiment is about 4 , displaying minor band formation.

\section{DISCUSSION}

As shown above, the CPPT treatments with low cooling rates effectively suppress band formation, even at a final cooling rate well below the critical cooling rate determined for continuous cooling. The effect is well reflected in the ASTM E1268-01AI index. However, to analyze the band formation in even more detail, a new parameter of 'band formation index' is defined similar to the one used for dielectrophoretically aligned PZT particles in a polymer matrix. ${ }^{[29]}$ To this aim, the micrographs are first processed using the Matlab image processing toolbox. ${ }^{[30]}$ The micrographs are transformed to binary images, and the sum of the darkness levels of all the pixels (having a dimension of $500 \times 500 \mu \mathrm{m}$ ) in every horizontal row is determined and normalized to the total number of pixels in each row. Pixels with a high darkness level indicate pearlite while pixels with a low 

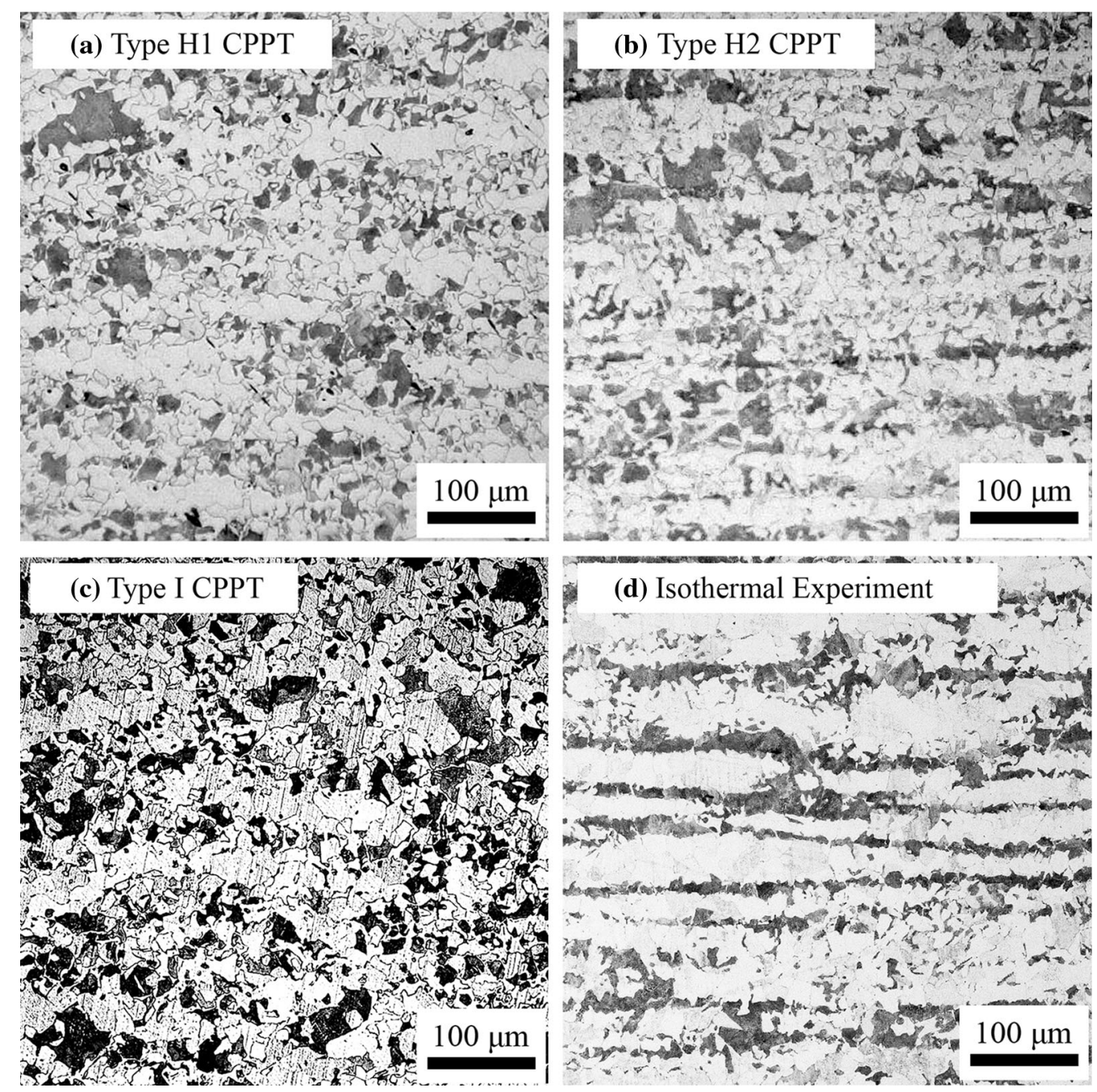

Fig. 6-Microstructures after different intercritical annealing routes of $(a)$ type H1 CPPT, $(b)$ type H2 CPPT, $(c)$ type I CPPT, and $(d)$ isothermal experiment all with $\mathrm{CR}=0.17 \mathrm{~K} / \mathrm{s}$.

darkness level correspond to ferrite grains. Peaks in the resulting spectrum correspond to the band position and the magnitude of sum is a measure of the quality of the band. The intercolumnar distance between the peaks shows the lateral distance between the formed bands. Results of applying the band formation indexing process to the microstructures after different intercritical treatment routes of type $\mathrm{H} 1$ (with $\mathrm{CR}=0.17,0.5$, and $1 \mathrm{~K} / \mathrm{s}$ ), $\mathrm{H} 2$ and I CPPT, isothermal experiment (with $\mathrm{CR}=$ $0.17 \mathrm{~K} / \mathrm{s}$ ), and corresponding CC experiments are presented in Figures 9(a) through (f). The curves for microstructures after $\mathrm{CC}$ experiments with $\mathrm{CR}=0.17$, 0.5 , and $1 \mathrm{~K} / \mathrm{s}$ in Figures 9(a) through (c) clearly show the peaks corresponding to the preferential nucleation and growth sites of pearlite grains in columns with a typical distance of $50 \mu \mathrm{m}$. The reduction of ratio of peak heights over the average values with increasing cooling rates in these graphs indicates the more uniform distribution of phases after CC experiments with higher cooling rates in spite of presence of broad bands.

The curves, for type H1 CPPT with CR $=0.17$ and $0.5 \mathrm{~K} / \mathrm{s}$ (Figures 9(a) and (b)), are significantly smoothed with a substantial reduction of the relative peak heights, indicative of the more uniform microstructure. The hills in the band formation index indicate that there are still preferential locations for pearlite formation with the typical distance of $50 \mu \mathrm{m}$. This indicates that $\mathrm{Mn}$ is still non-uniformly distributed along the microstructure, but for the cyclic annealing route, the formation of pearlite in preferential columns is strongly suppressed. The distinct peaks in type $\mathrm{H} 1$ with $\mathrm{CR}=$ $1 \mathrm{~K} / \mathrm{s}$ curve in Figure 9(c) are another indication of the anisotropic distribution of phases in microstructure after this treatment. As expected, the curves of band formation index for type $\mathrm{H} 1, \mathrm{H} 2$, and I CPPT routes with $\mathrm{CR}=0.17 \mathrm{~K} / \mathrm{s}$ shown in Figures 9(d) and (e) are flattened, while the curve of band formation index for isothermal experiment in Figure 9(f) clearly shows sharp separate peaks corresponding to diffusely banded and non-uniform microstructure.

As suggested above, despite the suppression of band formation after a CPPT treatment, the original inhomogeneous banded $\mathrm{Mn}$ distribution leading to band formation under conventional linear cooling conditions 
should still be present even after the CPPT treatment as the CPPT treatment only leads to $\mathrm{Mn}$ redistribution on a very local scale. In order to demonstrate this, a two-step route as shown in Figure 10(a) was designed where a fresh sample was first subjected to the type $\mathrm{H} 1$ treatment, cooled to room temperature, and then re-austenitized and cooled continuously at the rate of $0.17 \mathrm{~K} / \mathrm{s}$. Figure 10(b) shows the longitudinal dilatation curves recorded for the type $\mathrm{H} 1 \mathrm{CPPT}$ and subsequent $\mathrm{CC}$ experiment. The differences between type H1 CPPT and subsequent $\mathrm{CC}$ dilatations are similar to the ones in Figure 5(a) in which cyclic treatment and CC experiments were done in two different samples. During the CC experiment, austenite decomposes continuously, while in CPPT route, the austenite decomposition is retarded. The microstructure after the $\mathrm{CC}$ experiment (on a sample having first undergone the type $\mathrm{H}$ treatment) in Figure 10(c), shows a clearly banded microstructure. This confirms that the starting non-homogenous distribution of $\mathrm{Mn}$ in the material is preserved during the type H1 CPPT treatment and hence re-occurrence of the ferrite/pearlite band formation occurs in the following $\mathrm{CC}$ experiment.
The continuous cooling experiments show that in the hot-rolled alloy with micro-segregation of $\mathrm{Mn}$ and $\mathrm{Si}$, formation of ferrite/pearlite bands during continuous cooling from austenitic temperature is a virtual function of the applied cooling rate. As shown concisely in

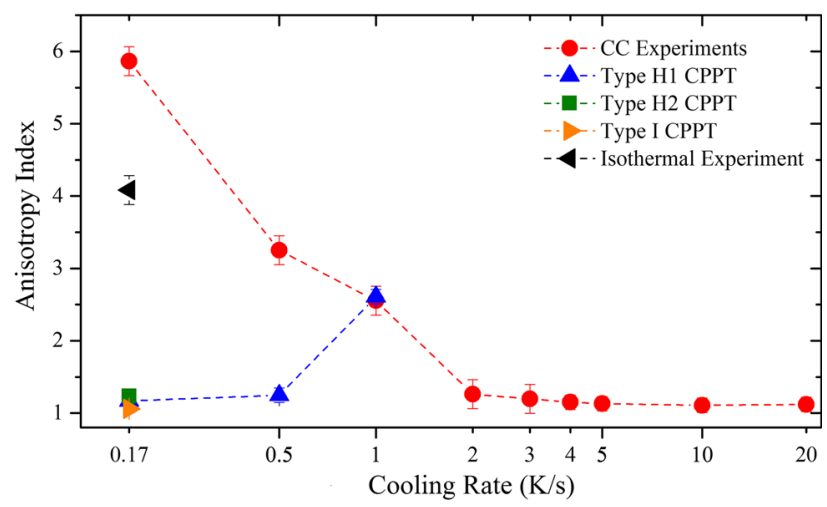

Fig. 8 - Standard anisotropy index for all the microstructures after different intercritical annealing and CC experiments vs the applied cooling rates.
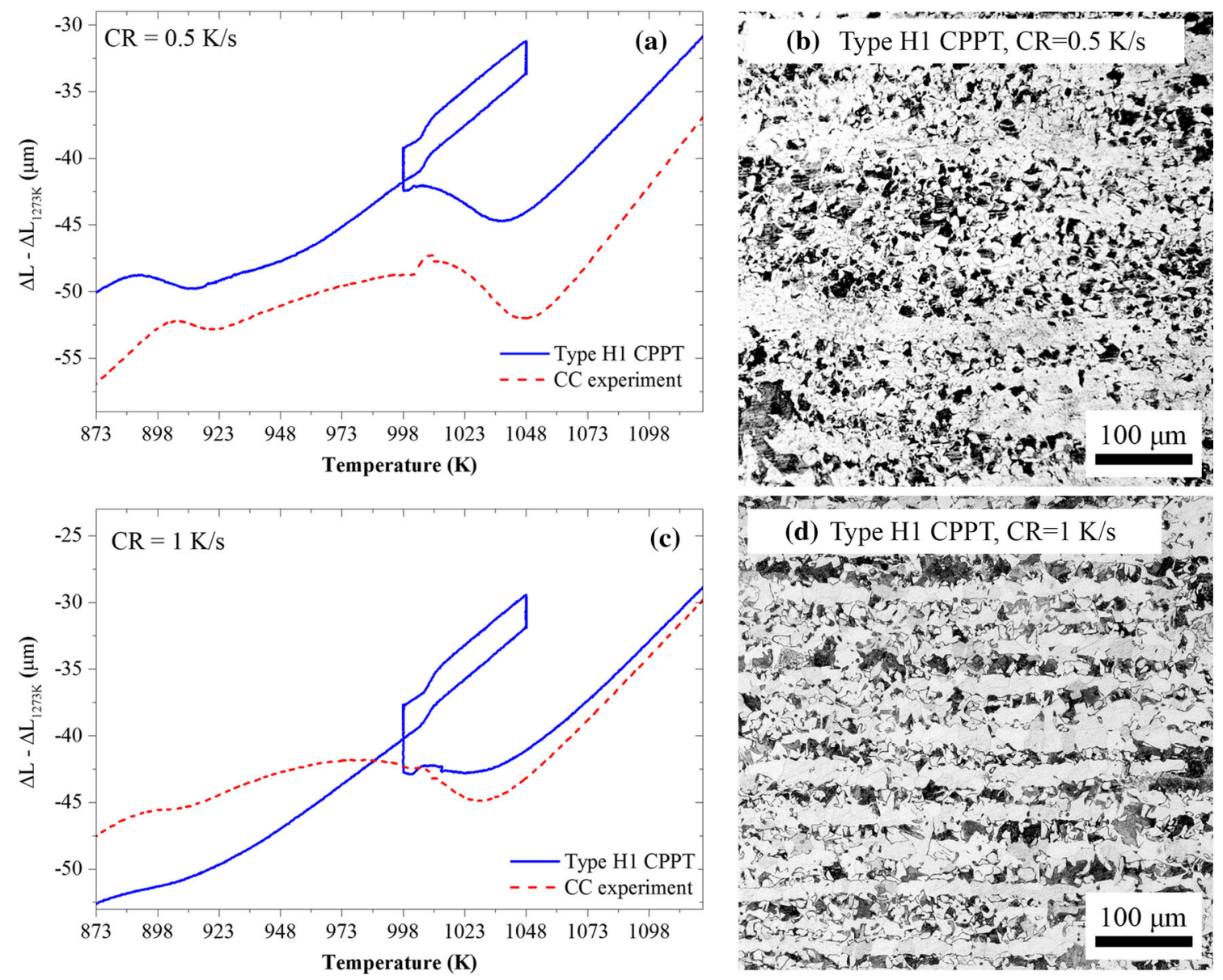

(d) Type $\mathrm{H} 1 \mathrm{CPPT}, \mathrm{CR}=1 \mathrm{~K} / \mathrm{s}$

Fig. 7- (a) longitudinal dilatation curves for type H1 CPPT experiments with CR $=0.5$ and $1 \mathrm{~K} / \mathrm{s},(b)$ microstructure after type H1 CPPT with $\mathrm{CR}=0.5 \mathrm{~K} / \mathrm{s},(c)$ lateral dilatation curves for type $\mathrm{H} 1 \mathrm{CPPT}$ experiments with $\mathrm{CR}=0.5$ and $1 \mathrm{~K} / \mathrm{s}$, and $(d)$ microstructure after type $\mathrm{H} 1$ $\mathrm{CPPT}$ with $\mathrm{CR}=1 \mathrm{~K} / \mathrm{s}$. 


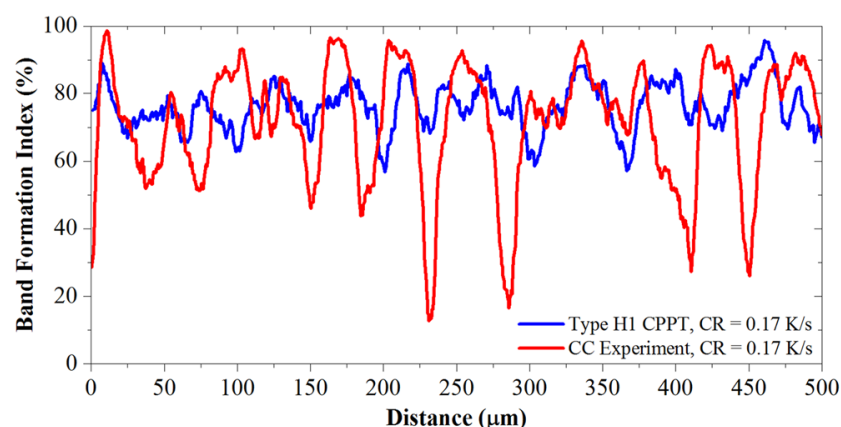

(a)

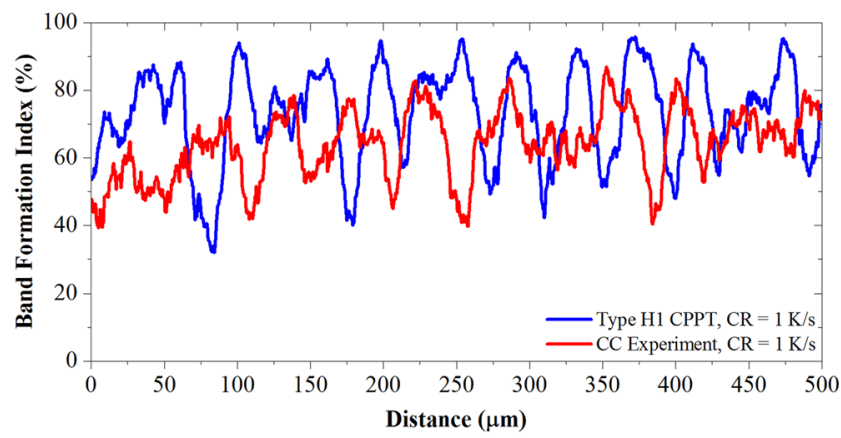

(c)

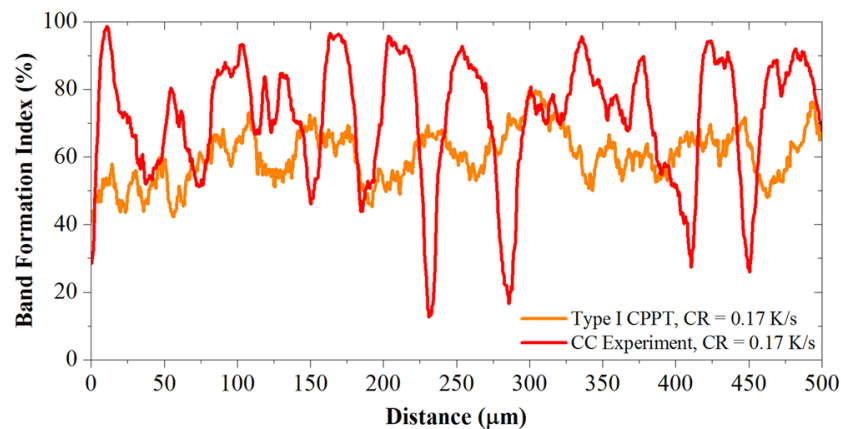

(e)

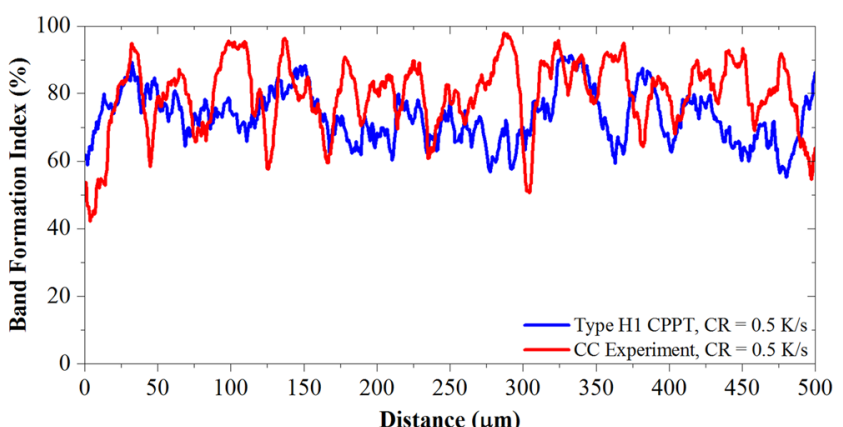

(b)

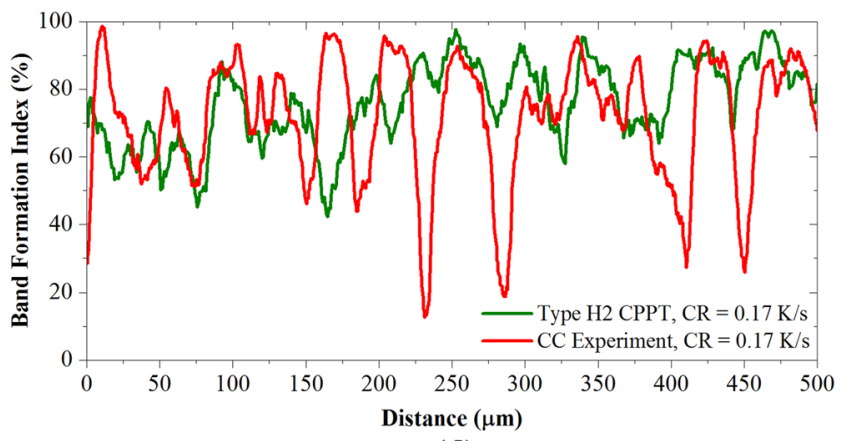

(d)

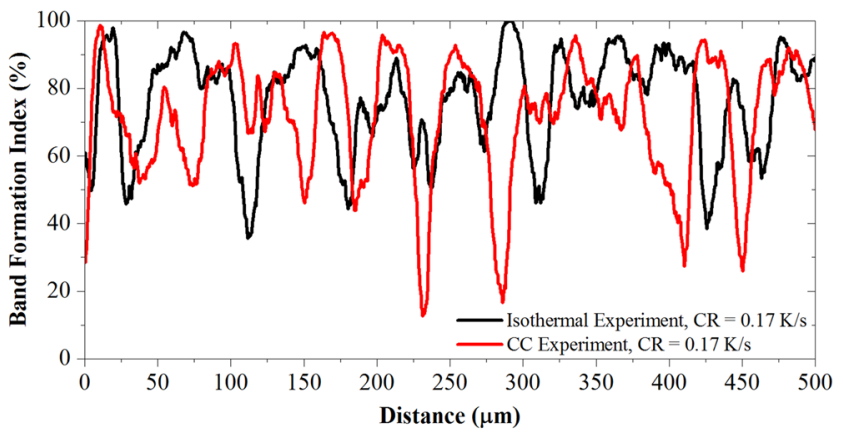

(f)

Fig. 9-Band formation index of microstructure $v s$ the distance along the normal to the rolling direction after $(a)$ type H1 CPPT with $\mathrm{CR}=0.17 \mathrm{~K} / \mathrm{s},(b)$ type $\mathrm{H} 1 \mathrm{CPPT}$ with $\mathrm{CR}=0.5 \mathrm{~K} / \mathrm{s},(c)$ type $\mathrm{H} 1 \mathrm{CPPT}$ with $\mathrm{CR}=1 \mathrm{~K} / \mathrm{s},(d)$ type H $2 \mathrm{CPPT}$ with $\mathrm{CR}=0.17 \mathrm{~K} / \mathrm{s},(e)$ type I $\mathrm{CPPT}$ with $\mathrm{CR}=0.17 \mathrm{~K} / \mathrm{s}$, and $(f)$ isothermal experiment with $\mathrm{CR}=0.17 \mathrm{~K} / \mathrm{s}$ and the $\mathrm{CC}$ experiments with similar CR.

Figure 8, cooling with rates equal or higher than $2 \mathrm{~K} / \mathrm{s}$ is essential to prevent the development of a banded microstructure. This is in agreement with earlier publications showing that even though the presence of micro-chemical segregation of $\mathrm{Mn} / \mathrm{Si}$ is a prerequisite for band formation, it is the kinetics of the phase transformation, and in particular that of the ferrite, which controls the actual formation of the microstructural bands. ${ }^{[5,18,31]}$ Pearlite grows much faster than the ferrite due to availability of higher driving force at lower transformation temperatures and with a shorter diffusion length as a result of the laminar pearlite structure. ${ }^{[4,5,3]}$ The time available for the growth of the ferrite controls the carbon enrichment of the austenite and this, for non-isothermal conditions, controls the chance of nucleation of either ferrite or pearlite in the Mn-rich and Mn-poor regions. For slow cooling rates, ferrite nucleation starts preferentially in the Mn-poor regions and the time for ferrite formation is long and the $\mathrm{C}$ partitions over relatively large distances. Hence, new ferrite nucleation will not occur in the Mn-rich regions assisting continuous pearlite formation in these regions. In general, for differences less than 6 to 8 pct in ferrite nucleation rate, banding does not take place. ${ }^{[5,32,33]}$

Interestingly, the nucleation conditions of both ferrite and pearlite (or bainite/martensite) can be derived from the dilatometric curves. The onset of the pearlite is most easily distinguishable in the lateral dilatation curves. ${ }^{[21]}$ The nucleation temperatures as a function of the cooling rate are shown in Figure 11. The usual linear relationship between onset temperature and cooling rate ${ }^{[34]}$ is obtained from this graph. Interestingly for this steel, the slope of the ferrite onset temperature does not change over the explored domain of cooling rated although the microstructure changes from a ferrite/pearlitic microstructure to a more pearlitic-bainitic/martensitic 

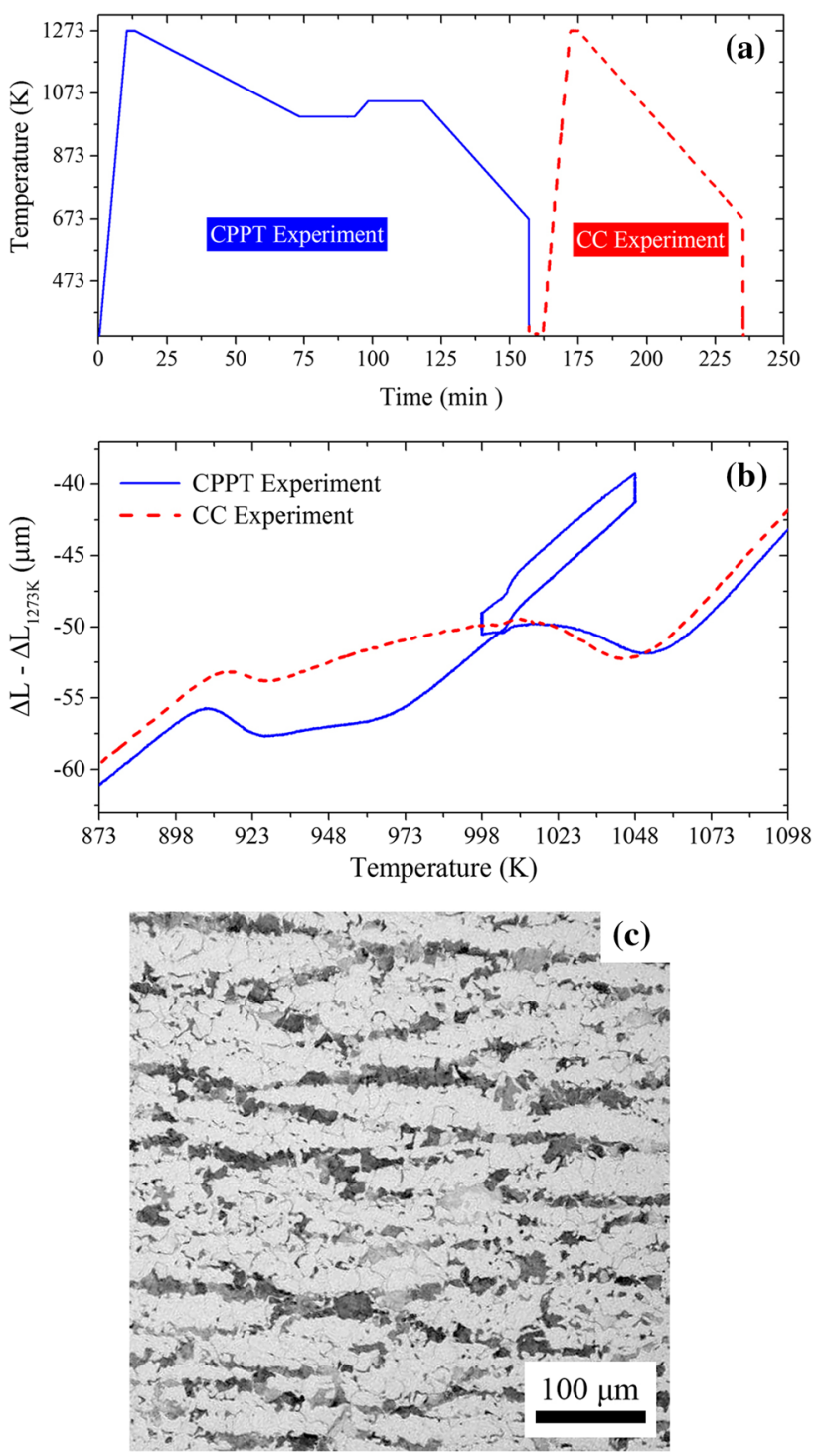

Fig. 10 - (a) Band recovery heat treatment route, (b) dilatation curves achieved with CPPT and CC experiments, and (c) microstructure after the $\mathrm{CC}$ experiment.

microstructure at around $10 \mathrm{~K} / \mathrm{s}$. Furthermore, the slope for the onset of the pearlite formation is equal to that of the ferrite onset temperature.

The experimental observations clearly show that the band formation can be suppressed by some of the CPPT treatments (see Figure 4), even for a low cooling rate of $0.17 \mathrm{~K} / \mathrm{s}$. The suppression is due to the ferrite formation being halted as a result of the local Mn enrichment at the moving austenite-ferrite interface and the spike of Mn left behind as a result of the cycling process. As the transformation is halted, there is less carbon enrichment and new ferrite formation can take place during the final cooling down. Thus, new ferrite formation can take place in the higher $\mathrm{Mn}$ regions and band formation is suppressed.

Figure 12 shows the total time spent on ferrite formation during cooling derived from dilatometry experiments $v_{s}$ the anisotropy index of the resulted microstructure after different CPPT and continuous cooling experiments. As explained above, in the presence of micro-chemical banding, isotropic microstructure with AI values close to 1 can only be achieved by continuous cooling with major time-constraint for ferrite formation achievable only through high cooling rates. In contrast, the CPPT treatments make formation of fully isotropic microstructures possible in case of long cooling down times.

As concisely shown in Figure 8, the values of AI very close to 1 for type $\mathrm{H} 1, \mathrm{H} 2$, and I CPPT routes with $\mathrm{CR}=0.17 \mathrm{~K} / \mathrm{s}$ indicate that a CPPT route such as that of type $\mathrm{H}$ in which the austenite-ferrite interface is forced to reverse its propagation direction, provides the conditions required for suppression of band formation.

In order to computationally investigate the effect of CPPT in controlling band formation, a Local Equilibrium (LE) thermodynamic model is used in a 1-D geometry with a size of $25 \mu \mathrm{m}$. Simulations of type H1 CPPT and CC experiments are performed with CR = $0.17 \mathrm{~K} / \mathrm{s}$ using the DICTRA software linked to TCFE7 and MOB2 databases, ${ }^{[35]}$ with the nominal composition set to $\mathrm{Fe}-0.17 \mathrm{C}-1.47 \mathrm{Mn}-1.48 \mathrm{Si}$ (all in mass pet). Figure 13(a) shows the position of austenite-ferrite interface $v s$ the transformation temperature achieved using LE model for both cyclic and CC experiments. In this graph, the position of the interface represents the fraction of formed ferrite. In agreement with the experimental results, the model predicts that during $\mathrm{CC}$ experiment the interface migrates smoothly during cooling. However, after the CPPT experiment, the interface becomes quasi-immobile up to the moment of a high undercooling. Figures 13(b) and (c) show the Mn and $\mathrm{C}$ profiles in the simulation cell at $T_{1}=998 \mathrm{~K}$ $\left(725^{\circ} \mathrm{C}\right)$ just before the final cooling. In the $\mathrm{CC}$ curves, there is a narrow Mn spike at the position of interface with incomplete redistribution of $\mathrm{C}$ in the remaining austenite. In the CPPT curves, the Mn spike is widened and carbon is firmly redistributed in the austenitic zone. During back transformation of ferrite to austenite in the reheating stage up to $T_{2}$, the interface leaves behind a spike of $\mathrm{Mn}$ in the austenite and due to diffusion of the $\mathrm{Mn}$ atoms, the spike starts to broaden and to form a narrow Mn-enriched zone. During final cooling after the thermal cycle, the austenite-ferrite interface has to pass through this enriched zone leading to a stagnation in the interface motion and hence a stagnation of the ferrite growth. ${ }^{[21,36]}$ In continuous cooling treatment from a fully austenitic state or after an interim isothermal treatment, this Mn spike at the interface also exists, but there is no reversion of interface and the austenite-ferrite interface does not have to transverse a previously Mn-enriched and now interface motion retarding zone.

Figure 14(a) shows an SEM micrographs of the microstructure after type H1 CPPT displaying a non-banded mixture of ferrite and pearlite grains. The actual width of this micrograph is about $130 \mu \mathrm{m}$ and includes three vertical micro-chemical bands of $\mathrm{Mn}$. Five different microstructural components can be defined in this graph:

(i) Ferrite grains at a lower Mn regions,

(ii) Pearlite grains in high Mn regions, 


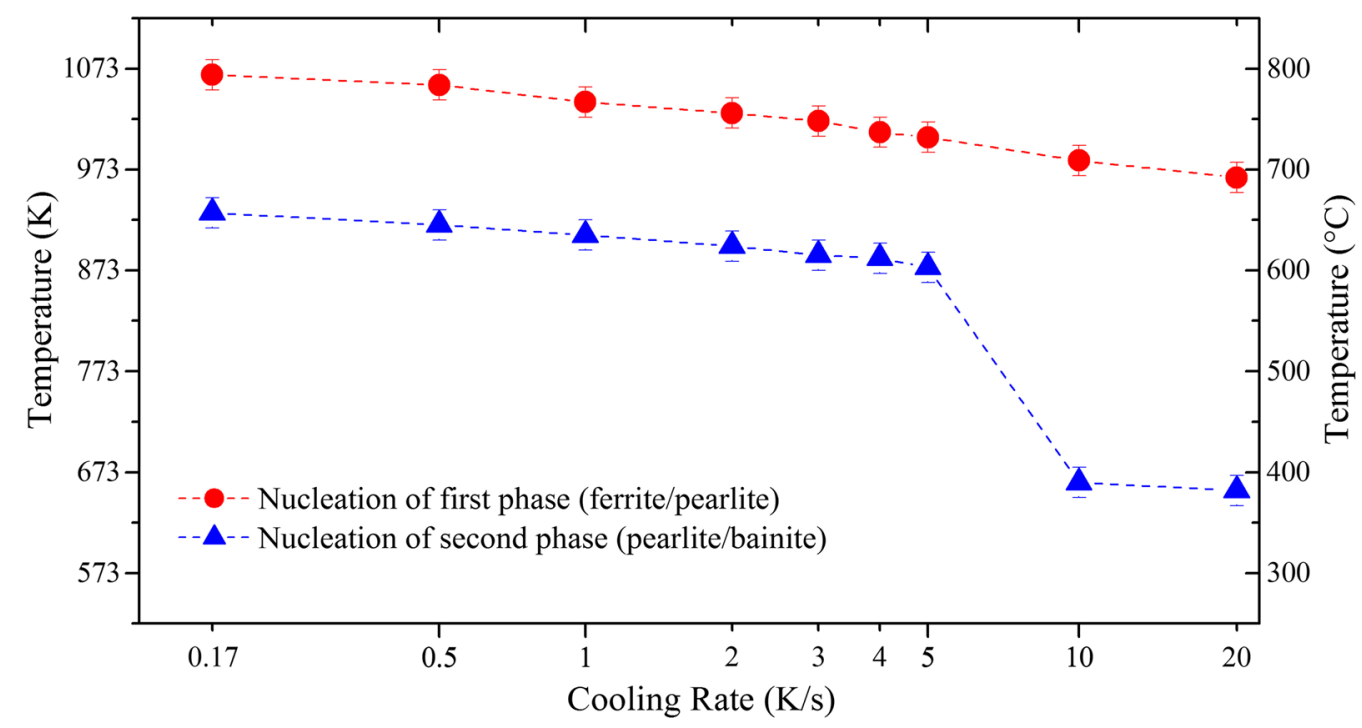

Fig. 11-Transformation onset of first phase (ferrite/pearlite) and second phase (pearlite/bainite/martensite) formation during continuous cooling.

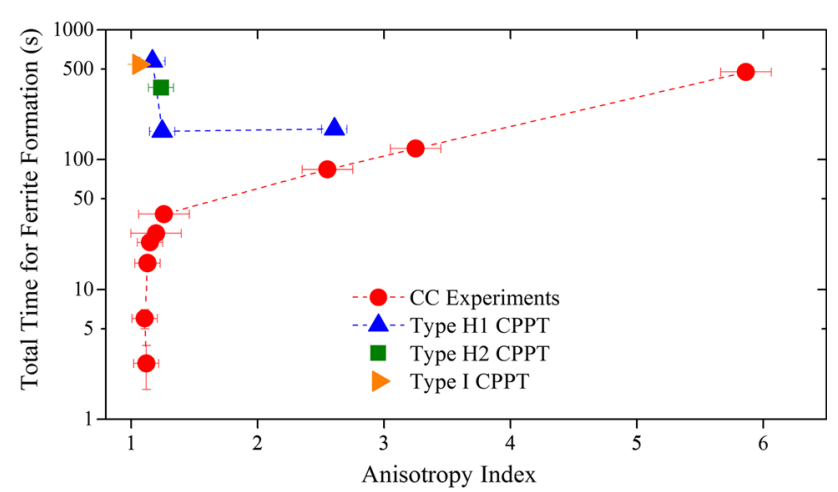

Fig. 12-Total time spent on ferrite formation in logarithmic scale $v s$ the anisotropy index of the resulted microstructure after different thermal treatments.

(iii) Pearlite rims in low Mn regions,

(iv) Pearlite islands in low $\mathrm{Mn}$ regions, and

(v) Ferrite grains in high $\mathrm{Mn}$ regions.

In a fully banded structure, the first two components dominate the microstructure. Formation of the last three components can be linked to an interrupted band formation process as a result of the CPPT treatment. Figure 14(b) shows a ferrite grain in a low Mn region with the so-called 'pearlite rims' perfectly aligned and decorating the ferrite grain and a 'pearlitic island' surrounded by different ferrite grains. The cementite lamella in the pearlite rim are more or less parallel all along the curved rim and indicates that the pearlite rim has a growth orientation relationship with the enclosed ferrite grain. As shown in Figure 13(b), with cyclic experiment, a bump of residual Mn forms opposing the migrating ferrite interface. If the size of remaining austenite is big enough, no saturation of carbon occurs in the austenite. When the ferrite front reaches this locally enriched $\mathrm{Mn}$, the interface is halted until further cooling provides sufficient driving force for the transformation, and the ferritic interface continues its growth in the form of pearlite. The thickness of $\sim 3 \mu \mathrm{m}$ of pearlite rims in Figure 14(b) is in good agreement with the width of residual Mn bump in Figure 13(b) predicted by the LE model.

In contrast, the pearlite islands consist of different growth orientations of cementite indicating that it has formed through several nucleation events. The pearlitic islands are small austenitic regions surrounded by growing ferrite fronts. As shown in Figure 13(c) by modeling, the incomplete ferrite transformation during cyclic experiment provides time for full carbon rejection from ferritic zones into some of the remaining austenite. During final cooling, as a result of high carbon content, these zones reach eutectoid composition and transform into isolated pearlitic islands.

The ferritic zones inside high $\mathrm{Mn}$ regions are the result of austenite back transformation during the cyclic experiments. Adjacent to ferrite grains formed in low $\mathrm{Mn}$ regions, new low carbon content austenite forms. During final cooling, the low carbon austenite region transforms into ferrite and prevents formation of continuous pearlite band in high $\mathrm{Mn}$ regions.

Figure 15 shows the line profiles for $\mathrm{C}, \mathrm{Mn}$, and $\mathrm{Si}$, as measured with EPMA across a rimmed ferrite grain and into a pearlite grain in a low $\mathrm{Mn}$ region of the sample having received a type $\mathrm{H} 1 \mathrm{CPPT}$ treatment with $\mathrm{CR}=0.17 \mathrm{~K} / \mathrm{s}$. The qualitative profiles of alloying elements show that $\mathrm{Si}$ concentration does not differ across different phases and the ferrite grain has low concentration of both $\mathrm{C}$ and $\mathrm{Mn}$. The pearlitic islands have a higher carbon content compared to the adjacent ferrite, but have similar Mn concentration. The pearlite rims have both high $\mathrm{C}$ and high $\mathrm{Mn}$ concentrations. This confirms that pearlite rims are locally enriched $\mathrm{Mn}$ zones formed by residual $\mathrm{Mn}$ concentrations explained above. 


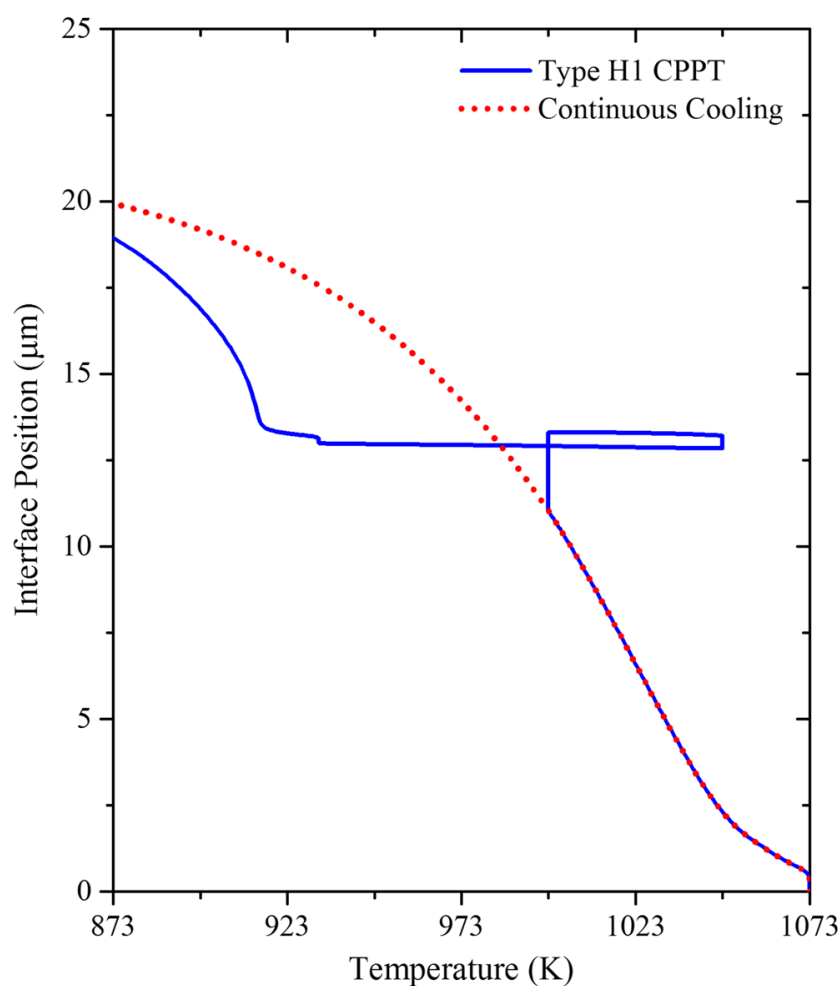

(a)

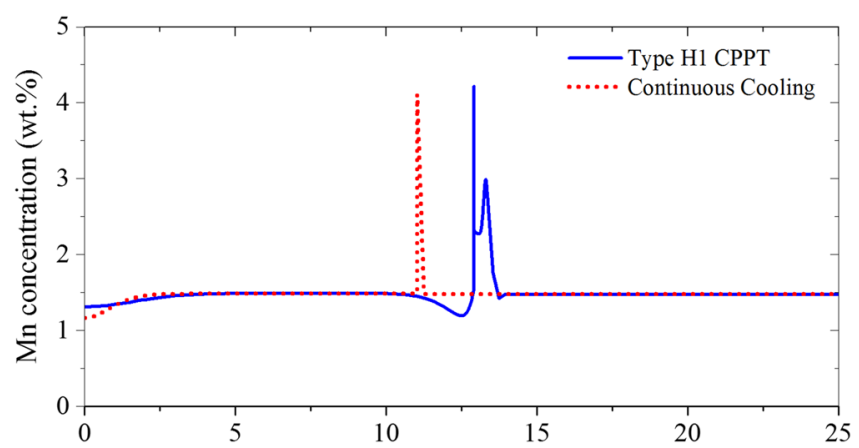

(b)

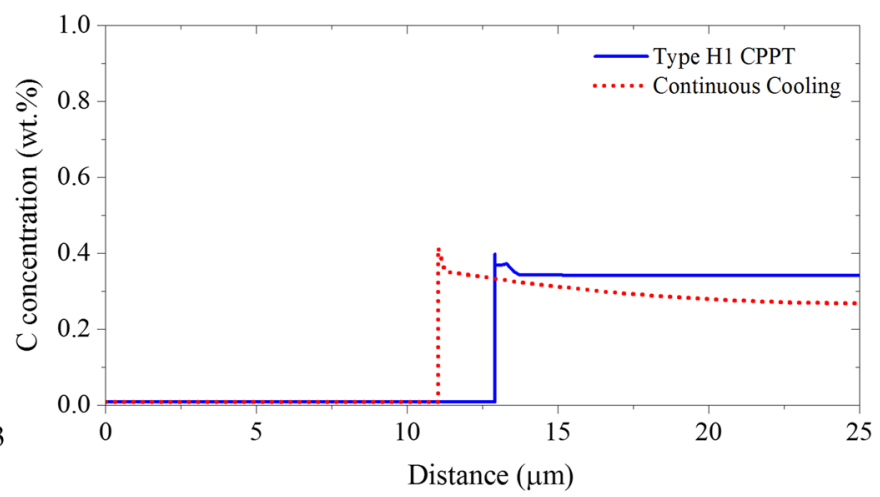

(c)

Fig. 13-Results of LE model prediction of type H1 CPPT and CC experiments with $\mathrm{CR}=0.17 \mathrm{~K} / \mathrm{s},(a)$ interface position vs temperature, $(b)$ $\mathrm{Mn}$ profile, and $(c) \mathrm{C}$ profile. The ferrite region is at the left side of interface in $\mathrm{Mn}$ and carbon profile.
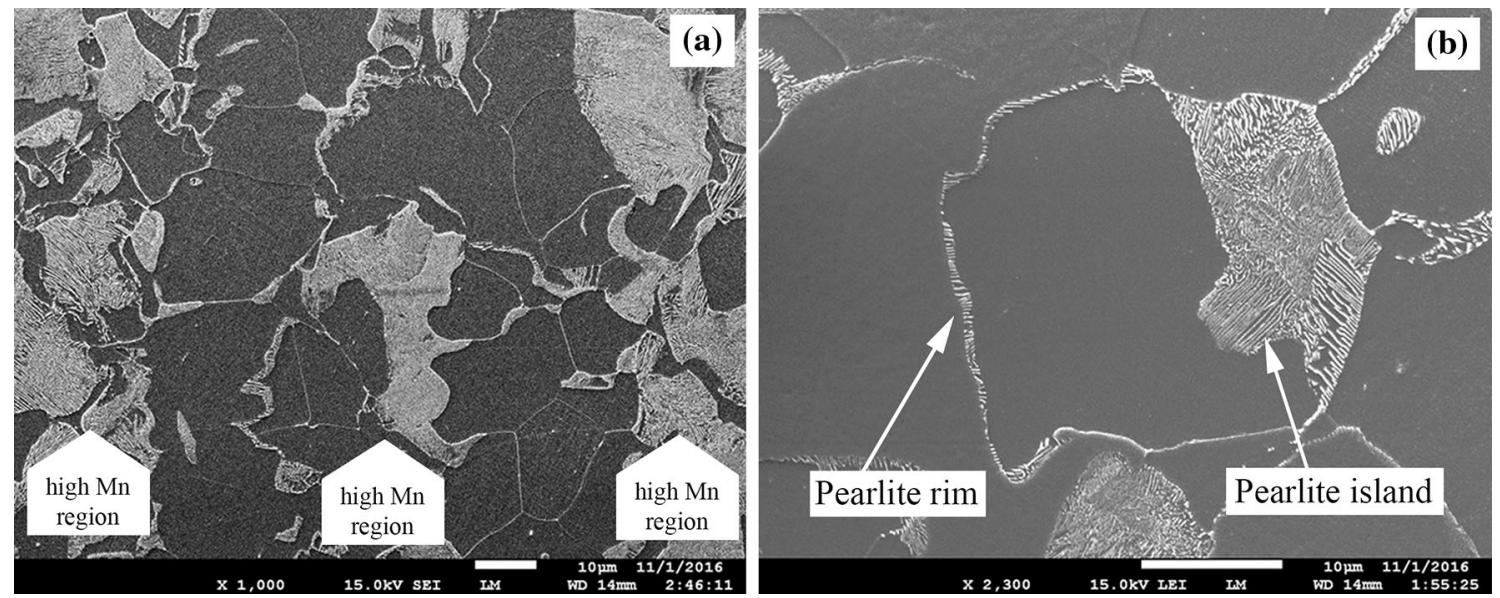

Fig. 14 - SEM micrographs after type H1 CPPT experiment with cooling rate of $0.17 \mathrm{~K} / \mathrm{s}$ showing $(a)$ ferritic and pearlitic grains in high and low $\mathrm{Mn}$ regions and $(b)$ ferrite grain pearlite rim and pearlite island in a low $\mathrm{Mn}$ region.

\section{CONCLUSIONS}

In this study, the effect of cooling rate on ferrite/pearlite band formation in a medium $\mathrm{Mn}$ alloy during continuous cooling experiments starting from the fully austenitic state is explored systematically. The experiments showed that for linear cooling band formation could only be suppressed by cooling at rates in excess of $2 \mathrm{~K} / \mathrm{s}$. However, when a cyclic partial phase transformation treatment in the intercritical domain was included in the final cooling down from the austenitic state, band formation was suppressed even at cooling rates as low as $0.17 \mathrm{~K} / \mathrm{s}$. Simple isothermal annealing in the intercritical region was found to have no effect on band formation tendency.

Based on all experiments, the following can be concluded:

1. Suppression of band formation during continuous cooling will only occur when the ferrite nucleation is 


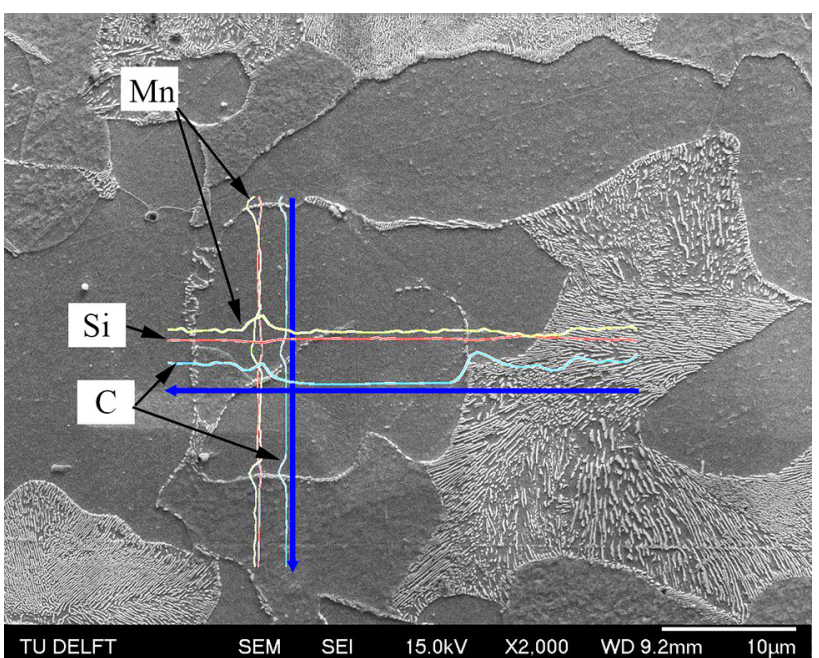

Fig. 15-EPMA measurements of composition after Type H1 CPPT experiment with $\mathrm{CR}=0.17 \mathrm{~K} / \mathrm{s}$, Carbon(= blue), $\mathrm{Mn}$ (yellow), and $\mathrm{Si}$ (dark red) (Color figure online).

promoted over the ferrite formation by the application of a higher cooling rate.

2. In case of an interim cyclic partial phase transformation in the intercritical region, the growth of the initially formed ferrite is significantly retarded such that new ferrite formation is made possible even in the case of a low cooling rate.

3. Controlled local enrichment of $\mathrm{Mn}$ at reversing austenite-ferrite interfaces during cyclic transformations is responsible for the suppression of ferrite growth leading to the prevention of ferrite/pearlite band formation even when a low cooling rate is applied.

4. The cyclic partial phase transformation can lead to the formation of pearlite rims not encountered in conventionally cooled material.

\section{ACKNOWLEDGMENTS}

This research was funded by ArcelorMittal, France. The authors acknowledge Dr. Didier Huin from ArcelorMittal for continuous support. They also thank Mr. C. Kwakernaak and Dr. W. G. Sloof, both at the Delft University of Technology, for the electron probe microanalysis measurements.

\section{OPEN ACCESS}

This article is distributed under the terms of the Creative Commons Attribution 4.0 International License (http://creativecommons.org/licenses/by/4.0/), which permits unrestricted use, distribution, and reproduction in any medium, provided you give appropriate credit to the original author(s) and the source, provide a link to the Creative Commons license, and indicate if changes were made.

\section{REFERENCES}

1. H. Song, S.S. Sohn, J.-H. Kwak, B.-J. Lee, and S. Lee: Metall. Mater. Trans. A, 2016, vol. 47A, pp. 2674-85.

2. A. Mayyas, A. Qattawi, M. Omar, and D. Shan: Renew. Sustain. Energy Rev., 2012, vol. 16, pp. 1845-62.

3. R. Kuziak, R. Kawalla, and S. Wanegler: Arch. Civ. Mech. Eng., 2008, vol. 8, pp. 103-17.

4. S.W. Thompson and P.R. Howell: Mater. Sci. Technol., 1992, vol. 8, pp. 777-84.

5. S.E. Offerman, N.H. van Dijk, M.T. Rekveldt, J. Sietsma, and S. van der Zwaag: Mater. Sci. Technol., 2002, vol. 18, pp. 297-303.

6. W. Xu, P.E.J. Rivera Díaz Del Castillo, and S. van der Zwaag: ISIJ Int., 2005, vol. 45, pp. 380-7.

7. R.A. Grange: Metall. Trans., 1971, vol. 2, pp. 417-26.

8. R. Feng, S. Li, X. Zhu, and Q. Ao: J. Alloys Compd., 2015, vol. 646, pp. 787-93.

9. Y. Karimi, S. Hossein Nedjad, G. Miyamoto, H. Shirazi, and T. Furuhara: Mater. Sci. Eng. A, 2017, vol. 697, pp. 1-7.

10. F.G. Caballero, A. García-Junceda, C. Capdevila, and C.G. De Andrés: Mater. Trans., 2006, vol. 47, pp. 2269-76.

11. J. Komenda and R. Sandström: Mater. Charact., 1993, vol. 31, pp. 143-53.

12. F.A. Khalid, M. Farooque, A. U1 Haq, and A.Q. Khan: Mater. Sci. Technol., 1999, vol. 15, pp. 1209-15.

13. R. Grossterlinden, R. Kawalla, U. Lotter, and H. Pircher: Steel Res., 1992, vol. 63, pp. 331-36.

14. J.S. Kirkaldy, J. von Destinon-Forstmann, and R.J. Brigham: Can. Metall. Q., 1962, vol. 1, pp. 59-81.

15. A. From and R. Sandström: Mater. Charact., 1998, vol. 41, pp. 11-26.

16. K. Mukherjee, L.S. Thomas, C. Bos, D.K. Matlock, and J.G. Speer: Mater. Sci. Forum, 2014, vols. 783-786, pp. 1067-72.

17. J.D. Verhoeven: J. Mater. Eng. Perform., 2000, vol. 9, pp. 286-96.

18. F.W. Y. Zhang, Y, H. Liu, X. Ruan, G. Li, L. Bai, Y.-L. Zhang, H.-Y. Liu, X.-J. Ruan, G.-Z. Li, L.-G. Bai, and F.-M. Wang: Beijing Keji Daxue Xuebao/Journal Univ. Sci. Technol. Beijing, 2009, vol. 31, pp. 199-206.

19. H. Chen and S. van der Zwaag: Metall. Mater. Trans. A, 2016, pp. $1-10$.

20. H. Chen, B. Appolaire, and S. van der Zwaag: Acta Mater., 2011, vol. 59 , pp. 6751-60.

21. H. Chen and S. van der Zwaag: Acta Mater., 2013, vol. 61, pp. 1338-49.

22. J. Zhu, R. Ding, J. He, Z. Yang, C. Zhang, and H. Chen: Scr. Mater., 2017, vol. 136, pp. 6-10.

23. T.A. Kop, J. Sietsma, and S. van der Zwaag: Mater. Sci. Technol., 2001, vol. 17, pp. 1569-74.

24. S.M.C. van Bohemen and L. Morsdorf: Acta Mater., 2017, vol. 125 , pp. $401-15$.

25. A. Verma, M. Sundararaman, J.B. Singh, and S.A. Nalawade: Meas. Sci. Technol., 2010, vol. 21, p. 105106.

26. Y. Liu, F. Sommer, and E. Mittemeijer: Thermochim. Acta, 2004, vol. 413 , pp. $215-25$.

27. G. Mohapatra, F. Sommer, and E.J. Mittemeijer: Thermochim. Acta, 2007, vol. 453, pp. 31-41.

28. ASTM E1268-01(2016): 2016.

29. M.A. Gutiérrez, H. Khanbareh, and S. van der Zwaag: Comput. Mater. Sci., 2016, vol. 112, pp. 139-46.

30. The Math Works Inc: 2007.

31. J.A. Eckert, P.R. Howell, and S.W. Thompson: J. Mater. Sci., 1993, vol. 28, pp. 4412-20.

32. P.E.J. Rivera Díaz Del Castillo, S. van der Zwaag, and J. Sietsma: Metall. Mater. Trans. A, 2004, vol. 35A, pp. 425-33.

33. P.E.J. Rivera-Díaz-del-Castillo and S. van der Zwaag: Steel Res. Int., 2004, vol. 75, pp. 711-15.

34. H.K.D.H. Bhadeshia: Met. Sci., 1982, vol. 16, pp. 159-66.

35. J.O. Andersson, T. Helander, L. Höglund, P. Shi, and B. Sundman: Calphad, 2002, vol. 26, pp. 273-312.

36. H. Chen and S. van der Zwaag: Philos. Mag. Lett. https://doi.org/ $10.1080 / 09500839.2011 .634840$ 